\title{
Short-range Li diffusion vs. long-range ionic conduction in nanocrystalline lithium peroxide batteries $\uparrow$
} ${ }_{2739}$ Cite this: Energy Environ. Sci, 2014, $7, \mathrm{Li}_{2} \mathrm{O}_{\mathbf{2}}$-the discharge product in lithium-air

\begin{abstract}
A. Dunst, ${ }^{\star a}$ V. Epp, ${ }^{\star a b}$ I. Hanzu, ab S. A. Freunberger ${ }^{a}$ and M. Wilkening ${ }^{\star a b}$
Understanding charge carrier transport in $\mathrm{Li}_{2} \mathrm{O}_{2}$, the storage material in the non-aqueous $\mathrm{Li}-\mathrm{O}_{2}$ battery, is key to the development of this high-energy battery. Here, we studied ionic transport properties and Li selfdiffusion in nanocrystalline $\mathrm{Li}_{2} \mathrm{O}_{2}$ by conductivity and temperature variable ${ }^{7} \mathrm{Li}$ NMR spectroscopy. Nanostructured $\mathrm{Li}_{2} \mathrm{O}_{2}$, characterized by a mean crystallite size of less than $50 \mathrm{~nm}$ as estimated from X-ray diffraction peak broadening, was prepared by high-energy ball milling of microcrystalline lithium peroxide with $\mu \mathrm{m}$ sized crystallites. At room temperature the overall conductivity $\sigma$ of the microcrystalline reference sample turned out to be very low $\left(3.4 \times 10^{-13} \mathrm{~S} \mathrm{~cm}^{-1}\right)$ which is in agreement with results from temperature-variable ${ }^{7}$ Li NMR line shape measurements. Ball-milling, however, leads to an increase of $\sigma$ by approximately two orders of magnitude $\left(1.1 \times 10^{-10} \mathrm{~S} \mathrm{~cm}^{-1}\right)$; correspondingly, the activation energy decreases from $0.89 \mathrm{eV}$ to $0.82 \mathrm{eV}$. The electronic contribution $\sigma_{\text {eon, }}$ however, is in the order of $9 \times 10^{-12} \mathrm{~S} \mathrm{~cm}^{-1}$ which makes less than $10 \%$ of the total value. Interestingly, ${ }^{7} \mathrm{Li} \mathrm{NMR}$ lines of nano- $\mathrm{Li}_{2} \mathrm{O}_{2}$ undergo pronounced heterogeneous motional narrowing which manifests in a two-component line shape emerging with increasing temperatures. Most likely, the enhancement in $\sigma$ can be traced back to the generation of a spin reservoir with highly mobile Li ions; these are expected to reside in the nearest neighbourhood of defects generated or near the structurally disordered and defect-rich interfacial regions formed during mechanical treatment.
\end{abstract}

Received 12th February 2014

Accepted 15th May 2014

DOI: $10.1039 / c 4 e e 00496 e$

www.rsc.org/ees

\section{Broader context}

Electrochemical energy storage is considered as the key technology to enable the shift from fossil to renewable energies. Among the few alternatives to Li-ion batteries that theoretically exceed significantly their specific energy, the non-aqueous $\mathrm{Li}-\mathrm{O}_{2}$ battery has attracted intense interest. It relies on the reversible formation of lithium peroxide in the positive electrode, $2 \mathrm{Li}^{+}+\mathrm{O}_{2}+2 \mathrm{e}^{-} \rightleftharpoons \mathrm{Li}_{2} \mathrm{O}_{2}$. Major challenges, however, face its practical realization. One is poor charge transport in $\mathrm{Li}_{2} \mathrm{O}_{2}$ that is widely recognized as a major factor limiting its achievable amount on the conductive substrate during discharge and the rate and overpotentials at which it can be formed and decomposed during cycling. So far, charge transport in $\mathrm{Li}_{2} \mathrm{O}_{2}$ is only poorly understood. To shed light on Li ion dynamics in $\mathrm{Li}_{2} \mathrm{O}_{2}$ it needs to be investigated in a complementary way by both macroscopic as well as microscopic techniques. In particular, Li NMR relaxometry offers an atomic-scale access to information on the elementary steps of ion hopping. Such results will build a first basis to understand the complex interplay of morphology, defect density and ion transport in $\mathrm{Li}_{2} \mathrm{O}_{2}$. They may help to improve the key metrics of the $\mathrm{Li}^{-} \mathrm{O}_{2}$ battery, such as capacity, rate and efficiency.

\section{Introduction}

The development of new energy storage systems is a vital topic in materials science. In particular, the lithium-air battery causes tremendous interest not only from the part of scientific

${ }^{a}$ Christian Doppler Laboratory for Lithium Batteries, Institute for Chemistry and Technology of Materials, Graz University of Technology, Stremayrgasse 9, 8010 Graz, Austria.E-mail: andreas.dunst@tugraz.at; vikror.epp@tugraz.at; wilkening@ tugraz.at

${ }^{b}$ DFG Research Unit 1277, Graz University of Technology, Stremayrgasse 9, 8010 Graz, Austria

$\dagger$ Electronic supplementary information (ESI) available. See DOI: 10.1039/c4ee00496e community but also from an industrial point of view. ${ }^{\mathbf{1 - 5}}$ The theoretical specific energy of non-aqueous lithium air batteries is ca. $3500 \mathrm{~W} \mathrm{~h} \mathrm{~kg} \mathrm{Li}_{2} \mathrm{O}_{2}$ based on the mass of active materials alone. Therefore, it significantly exceeds that of lithium-ion batteries with conventional insertion materials. ${ }^{6-10}$ Potential key applications, particularly in the long term, include electric vehicles as well as the storage of electricity from intermittent sources such as wind, solar, and tidal.

On discharge, at the positive electrode $\mathrm{O}_{2}$ from the atmosphere enters the porous electrode, is dissolved in the nonaqueous electrolyte within the pores, and is reduced at the electrode surface forming solid lithium peroxide. $\mathrm{Li}_{2} \mathrm{O}_{2}$ can be (re-)oxidized upon charging., ${ }^{\mathbf{1 , 7 , 8 1 0}}$ The achievable amount of 
$\mathrm{Li}_{2} \mathrm{O}_{2}$ that can reversibly be formed upon discharge inside the porous electrode governs the reversible capacity. While the principal possibility to electrochemically form and decompose $\mathrm{Li}_{2} \mathrm{O}_{2}$ in non-aqueous electrolytes is well established, many challenges remain towards practical application.,.$^{\mathbf{1 , 2 , 6 - 8 , 1 1 , 1 2}}$ These include stability issues of the electrolyte and the porous electrode that lead to side reactions and compromised cycleability. ${ }^{13-19}$ Typical side reaction products at the cathode are $\mathrm{Li}_{2} \mathrm{CO}_{3}$, Li alkyl carbonates and Li carboxylates. ${ }^{13,17,20,21}$

Another major challenge is how to form a large amount of solid, insulating $\mathrm{Li}_{2} \mathrm{O}_{2}$ by $\mathrm{O}_{2}$ reduction in the conductive porous substrate and to effectively oxidize it on charging.. ${ }^{2-26}$ On discharge, formation of a film of insulating $\mathrm{Li}_{2} \mathrm{O}_{2}$ limits the film thickness to a few $\mathrm{nm}$ before electron tunnelling or bulk conduction becomes ineffective. ${ }^{23,24,27}$ This is because of the poor conductivity estimated for pure $\mathrm{Li}_{2} \mathrm{O}_{2}$ that is significantly lower than that of other battery materials. In many cases particle growth has been observed that typically leads to particles in the range of 200 to $400 \mathrm{~nm}$ composed of a few $10 \mathrm{~nm}$ large primary crystallites; this suggests additional transport mechanisms to be in place. ${ }^{5,28}$ On charging, a two-stage process has been disclosed involving $\mathrm{Li}^{+}$removal near the surface and bulk $\mathrm{Li}_{2} \mathrm{O}_{2}$ oxidation at low and high overpotentials, respectively. ${ }^{24,25,29}$ This requires Li motion in the surface region of $\mathrm{Li}_{2} \mathrm{O}_{2}$ and electron transport from the $\mathrm{Li}_{2} \mathrm{O}_{2}$ to the solid electron conducting surface. Electron transport may be relatively easy for $\mathrm{Li}_{2} \mathrm{O}_{2}$ directly in contact with the surface, but becomes difficult for the majority of $\mathrm{Li}_{2} \mathrm{O}_{2}$ more remote from the surface. When we consider issues such as the reversibility of $\mathrm{Li}$ peroxide accumulation and removal, it can be seen that transport in the solid state, that is, in the bulk, plays a major role. In general, enhanced Li diffusion in the bulk may assist in the electrochemical formation as well as the resorption and dissolution of Li peroxide. Considering recent studies, both electron and ion transport in $\mathrm{Li}_{2} \mathrm{O}_{2}$ are shown to be critical for the operation of the Li-air battery and improvements require their understanding on a microscopic level. ${ }^{5,26,30,31}$ In particular, it has been shown recently that finely crystalline or amorphous $\mathrm{Li}_{2} \mathrm{O}_{2}$ decomposes at lower voltages than large particles. The exact reasons, however, have not been identified yet. ${ }^{5,31}$

In addition to these recent findings, there is a lively debate on charge transport properties in $\mathrm{Li}_{2} \mathrm{O}_{2}$ in general; several theoretical studies have been published until now ${ }^{23,24,32-35}$ including also a very recent one on amorphous $\mathrm{Li}_{2} \mathrm{O}_{2}$ by Siegel and co-workers. ${ }^{36}$ As yet, only Maier and co-workers ${ }^{37}$ have investigated electron and ion transport in microcrystalline $\mathrm{Li}_{2} \mathrm{O}_{2}$ experimentally by ac impedance spectroscopy and dc measurements; they showed that electronic conduction is governed by hole polarons, and ionic conduction is presumably mediated by negatively charged lithium vacancies; the crystal structure of $\mathrm{Li}_{2} \mathrm{O}_{2}$ (space group $P 6_{3}$ / $m m c$ ) is shown in Fig. 1. To the best of our knowledge, there is, so far, no investigation available reporting on activation energies of the elementary hopping processes of individual Li ions. Such information can be made available by nuclear magnetic resonance (NMR) spectroscopy.

The present work is aimed at understanding both shortrange and long-range $\mathrm{Li}$ ion transport in nanocrystalline $\mathrm{Li}_{2} \mathrm{O}_{2}$, a)

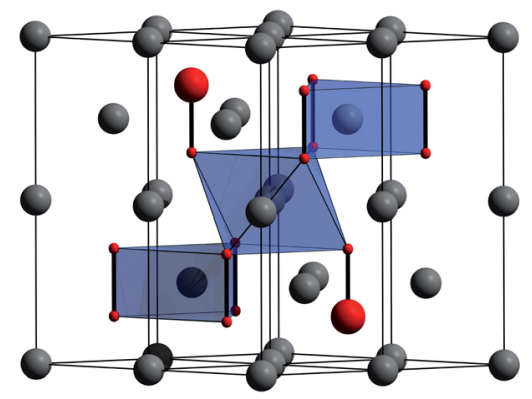

b)

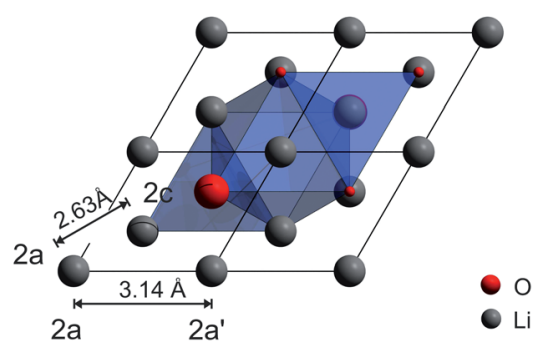

Fig. 1 Crystal structure of $\mathrm{Li}_{2} \mathrm{O}_{2}$ (hexagonal space group $P 6_{3} / m m c$ ), see also ref. 24 . (a) $2 \times 2 \times 1$ expansion of the unit cell. The covalently bonded $\mathrm{O}_{2}$ dimers are arranged in an alternating $\mathrm{ABAB}$ stacking. There are two unique $\mathrm{Li}$ sites indicated by polyhedra. The trigonal prismatic $\mathrm{Li}$ is in the same layer as the peroxide anions. The octahedrally coordinated one resides between the peroxide layers. (b) View along the $z-$ axis showing the $\mathrm{Li}-\mathrm{Li}$ distances of the two crystallographically inequivalent $\mathrm{Li}$ sites $2 \mathrm{a}$ and $2 \mathrm{C}$.

that is, a nanostructured sample with crystallites having a mean diameter of less than $50 \mathrm{~nm}$ which is comparable to that found in electrochemically formed $\mathrm{Li}_{2} \mathrm{O}_{2}$. The samples investigated have been prepared ex situ via a top-down approach: chemically synthesised microcrystalline lithium peroxide was mechanically treated in a high-energy planetary ball mill. The starting material was obtained in high purity by dehydration of a mixture of $\mathrm{LiOH}$ and $\mathrm{H}_{2} \mathrm{O}_{2}$. Although composed of crystallites with the same mean diameter, a nanocrystalline sample prepared by ball-milling is not directly comparable with the discharge product formed in a lithium-air battery. Here, however, we considered ball milling as an appropriate means to resemble the electrochemically formed $\mathrm{Li}_{2} \mathrm{O}_{2}$ as closely as possible with respect to both crystallite size and defects. From the point of view of structural disorder, the sample investigated might serve well to study the influence of structural disorder on ion transport properties. As has been shown also for other $\mathrm{Li}$ ion conductors, the transport properties of ball milled oxides may also resemble those of completely amorphous materials reflecting the upper limit of a disordered oxide or peroxide.

In the present study, long-range as well as short-range Li ion dynamics have been probed by temperature-variable conductivity spectroscopy and ${ }^{7} \mathrm{Li}$ NMR relaxometry. The overall conductivity $\sigma_{\mathrm{dc}}$ of the microcrystalline sample turned out to be very low which is in agreement with previous results as well as with ${ }^{7} \mathrm{Li}$ NMR line shape measurements presented here. Ballmilling, however, leads to an increase of $\sigma_{\mathrm{dc}}$, being characteristic for long-range ion transport, by approximately two orders 
of magnitude; correspondingly, the activation energy decreases. Similarly, also short-range Li ion dynamics are influenced by high-energy ball milling. In general, a large volume fraction of interfacial regions is formed and structural disorder is introduced by mechanical treatment. The defects generated are anticipated to largely influence both ionic transport over long distances as well as the elementary steps of ion hopping to which NMR is extremely sensitive when carried out at sufficiently low temperatures.

\section{Experimental}

\section{A. Preparation, structural and thermal characterization of lithium peroxide}

Lithium hydroxide monohydrate (Sigma Aldrich) was dissolved in water (dest.) and an equimolar aqueous solution of hydrogen peroxide 30\% (Merck) was added under an Ar atmosphere. The solution was stirred under an argon atmosphere at ambient conditions. The initially produced lithium hydroperoxide LiOOH was dried in vacuo and subsequently treated at $493 \mathrm{~K}$ for $12 \mathrm{~h}$ yielding microcrystalline lithium peroxide $\mathrm{Li}_{2} \mathrm{O}_{2}$ of high purity. To prepare nanocrystalline $\mathrm{Li}_{2} \mathrm{O}_{2}$, the source material micro- $\mathrm{Li}_{2} \mathrm{O}_{2}$ was mechanically treated in a high-energy ball mill (Fritsch Pulverisette 7 (premium line)). A grinding beaker made of stabilized $\mathrm{ZrO}_{2}(45 \mathrm{~mL})$ and 140 milling balls $\left(\mathrm{ZrO}_{2}, 5 \mathrm{~mm}\right.$ in diameter) were employed; the microcrystalline starting sample was milled for $180 \mathrm{~min}$ at a rotational speed of $600 \mathrm{rpm}$. The complete synthesis was carried out under an Ar atmosphere.

From then on, the samples prepared were stored in an argonfilled glove box. They were characterized by X-ray powder diffraction (XRD) carried out at room temperature with a Bruker D8 Advance diffractometer operating in Bragg-Brentano geometry with $\mathrm{Cu}-\mathrm{K}_{\alpha}$ radiation at $40 \mathrm{kV}$. Diffractograms were analyzed by Rietveld refinement with the programs FULLPROF and X'PertHighScorePlus (Panalytical). To determine decomposition temperatures we carried out thermogravimetric (TG) and differential scanning calorimetry (DSC) measurements; for simultaneous thermal analysis a 449C Jupiter (Netzsch) was used. The heating rate was $10 \mathrm{~K} \mathrm{~min}^{-1}$ from $293 \mathrm{~K}$ to $773 \mathrm{~K}$; experiments were carried out with a helium gas stream of $50 \mathrm{~mL} \mathrm{~min}{ }^{-1}$.

\section{B. Characterization of ion transport and Li diffusivity}

1. Impedance analysis and polarization measurements. For the impedance measurements a Novocontrol Concept 80 broadband dielectric spectrometer equipped with an Alpha-A analyzer was employed. Conductivities were measured under an inert gas atmosphere produced by fresh evaporation of dry nitrogen gas ( $1 \mathrm{~atm}$ ) within a ZGS active sample cell which is capable to measure conductivities down to $10^{-14} \mathrm{~S}$ at frequencies ranging from $3 \mu \mathrm{Hz}$ to $20 \mathrm{MHz}$. A Quattro cryosystem (Novocontrol) was employed for temperature regulation with an accuracy of $c a$. $0.5 \mathrm{~K}$. For impedance measurements the powder samples were cold-pressed (P.O. Weber press) with a uniaxial pressure of $30 \mathrm{kN}$ to cylindrical pellets ( $8 \mathrm{~mm}$ in diameter, approximately $1 \mathrm{~mm}$ in thickness). Electrodes were applied by plasma Au sputtering (Leica EM
SCD050). Complex impedance data were recorded at temperatures ranging from $133 \mathrm{~K}$ to $573 \mathrm{~K}$.

In order to estimate the ionic and electronic contributions to the total conductivity, potentiostatic polarization measurements were carried out on the gold-sputtered $\mathrm{Li}_{2} \mathrm{O}_{2}$ pellets which were pressed under a protective Ar atmosphere. The pellets were placed inside air-tight Swagelok-type electrochemical cells in order to protect them during measurements from air and humidity. The polarization experiments were carried out at $293 \mathrm{~K}$ with a VMP3 instrument from Biologic that was equipped with a low-current option and controlled by EClab software. Polarization measurements were carried out with a constant voltage $U=5 \mathrm{~V}$. The current $I$ was recorded as a function of time $t$.

2. NMR spectroscopy. Temperature-variable and frequencydependent ${ }^{7} \mathrm{Li}$ NMR measurements were recorded with an Avance III spectrometer (Bruker BioSpin) connected to a shimmed cryomagnet with a nominal magnetic field of $7.04 \mathrm{~T}$ corresponding to a resonance frequency $\omega_{0} / 2 \pi$ of $116.5 \mathrm{MHz}$. A commercial high temperature probe (Bruker Biospin) was employed allowing $\pi / 2$ pulse lengths of about $2.5 \mu$ s.

Prior to the measurements, the samples were fire-sealed in evacuated glass NMR tubes of $5 \mathrm{~mm}$ in diameter and $c a .3 \mathrm{~cm}$ in length. The measurements were carried out at temperatures ranging from $133 \mathrm{~K}$ to $604 \mathrm{~K}$. Temperature regulation and monitoring were carried out with a Eurotherm temperature controller in combination with a type $\mathrm{T}$ thermocouple.

${ }^{7} \mathrm{Li}$ NMR spectra were obtained after Fourier transformation of the free induction decays (FIDs) recorded by a single pulse experiment using recycle delays of up to $60 \mathrm{~s}$ at the lowest accessible temperatures. ${ }^{7} \mathrm{Li}$ NMR spin-lattice relaxation (SLR) rates $R_{1}$ in the laboratory frame of reference were acquired by means of the classical saturation recovery pulse sequence $10 \times$ $\pi / 2-t_{\mathrm{d}}-\pi / 2-$ acquisition (acq.) ${ }^{38-42}$ The initial ten $\pi / 2$ pulses in rapid succession are used to destroy any longitudinal magnetization $M_{z}$. Immediately after this saturation comb, the recovery of $M_{z}$ is recorded as a function of delay time $t_{\mathrm{d}}$ at different temperatures. In addition, ${ }^{7} \mathrm{Li}$ NMR SLR rates have also been recorded in the rotating frame of reference (SLR $\rho$ ). For this purpose, the spin-locking technique $\pi / 2 p\left(t_{\text {lock }}\right)-$ acq. ${ }^{\mathbf{3 8 4 3 - 4 8}}$ was employed. The corresponding locking frequency was chosen to be $\omega_{1} / 2 \pi=28 \mathrm{kHz}$ with the duration of the locking pulse $t_{\text {lock }}$ varying from $100 \mu \mathrm{s}$ to $100 \mathrm{~ms}$. The recycle delay was set to at least $5 \times R_{1}{ }^{-1} \equiv 5 \times T_{1}$ in order to guarantee full longitudinal relaxation between each scan. Both $R_{1}$ and $R_{1 \rho}$ were obtained by parameterizing the resulting magnetic transients $M_{z}\left(t_{\mathrm{d}}\right)$ and $M_{\mathrm{Q}}\left(t_{\text {lock }}\right)$, respectively, by stretched exponentials: $M_{z}\left(t_{\mathrm{d}}\right) \propto 1-\exp \left(-\left(t_{\mathrm{d}} / T_{1 \mathrm{\varrho}}\right)^{\gamma}\right)$ and $M_{\mathrm{\varrho}}\left(t_{\text {lock }}\right) \propto$ $\exp \left(-\left(t_{\text {lock }} / T_{1 \mathrm{e}}\right)^{\gamma_{\mathrm{e}}}\right)$, respectively.

In addition, ${ }^{7} \mathrm{Li}$ NMR stimulated echoes $^{49-53}$ have been recorded by utilizing the Jeener-Broekaert ${ }^{54}$ pulse sequence as a function of mixing time $t_{\mathrm{m}}\left(10 \mu \mathrm{s} \leq t_{\mathrm{m}} \leq 100 \mathrm{~s}\right)$ at a fixed preparation time $t_{\mathrm{p}}:\left(90^{\circ}\right)_{x}-t_{\mathrm{p}}-\left(45^{\circ}\right)_{y}-t_{\mathrm{m}}-\left(45^{\circ}\right)-t-$ acquisition. Note that SAE NMR, that is, two-time correlation spectroscopy, takes advantage of interactions between the quadrupole moment of the nucleus and the electric field gradient (EFG) tensor at the nuclear site. ${ }^{55}$ The technique gives 
access to single-particle correlation functions, so-called ${ }^{7} \mathrm{Li}$ sinsin hopping correlation functions. In general, the results from stimulated echo measurements are comparable to those from SLR $\rho$ NMR measurements. ${ }^{53}$ The difference is that Li SAE NMR, being comparable to $\mathrm{Li}$ exchange $\mathrm{NMR},{ }^{56-60}$ is sensitive to even slower Li diffusion processes.

\section{Results and discussion}

\section{A. X-ray diffraction, chemical and thermal analysis}

The purity of the lithium peroxide prepared was checked by X-ray powder diffraction (see Fig. 2), energy dispersive X-ray diffraction (EDX), infrared (IR) spectroscopy and inductively coupled plasma mass spectrometry (ICP-MS). The powder diffractogram obtained for microcrystalline $\mathrm{Li}_{2} \mathrm{O}_{2}$ can be fully indexed with literature $2 \theta$ values. We could not detect any significant amounts of crystalline impurity phases. Fortunately, the same is true for the ball-milled material which was treated for $3 \mathrm{~h}$ in a planetary mill. It has also been characterized by XRD, EDX, IR spectroscopy and ICP-MS (see also the ESI†). As expected, the XRD peaks have broadened due to size effects and strain generated, but neither any mechanochemically induced phases were formed nor any traces of crystalline impurities,

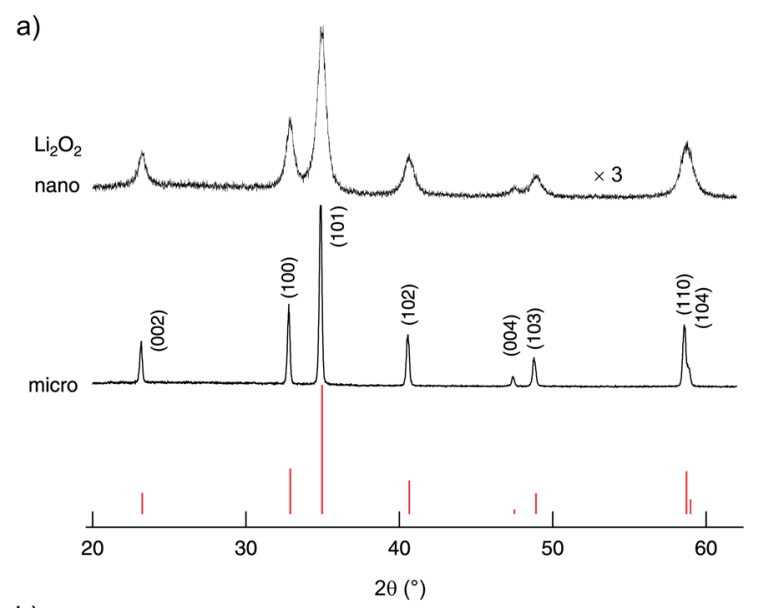

b)

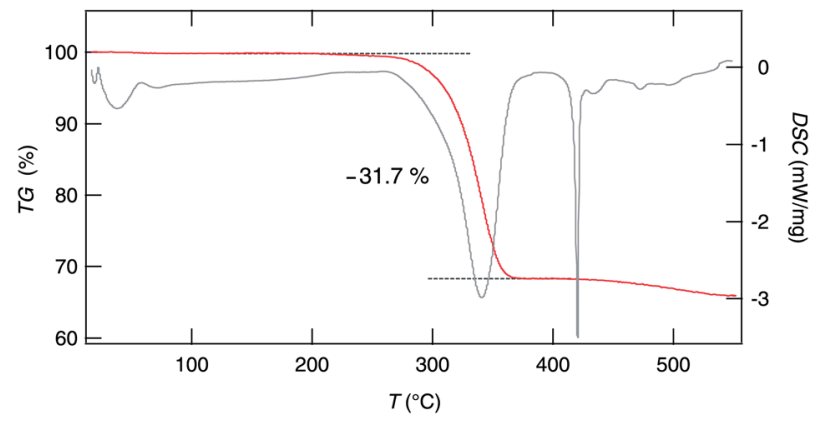

Fig. 2 (a) X-ray powder diffractograms of micro- and nanocrystalline lithium peroxide. Miller indices $(h k l)$ indicate the reflections of $\mathrm{Li}_{2} \mathrm{O}_{2}$. Vertical bars in the lower part of the figure illustrate peak positions and relative intensities of pure lithium peroxide. Compared to the pattern of micro- $\mathrm{Li}_{2} \mathrm{O}_{2}$ that of nano- $\mathrm{Li}_{2} \mathrm{O}_{2}$ is magnified by a factor of three. (b) $\mathrm{TG}$ (red line) and DSC measurements (grey line) of nano- $\mathrm{Li}_{2} \mathrm{O}_{2}$; above ca. $500 \mathrm{~K} \mathrm{Li}_{2} \mathrm{O}_{2}$ starts to decompose. A weight loss of ca. $32 \%$ points to the release of oxygen leaving over $\mathrm{Li}_{2} \mathrm{O}$. such as abrasion of $\mathrm{ZrO}_{2}$, show up. Negligible abrasion is also corroborated by ICP-MS (see ESI†). IR spectroscopy (see Fig. S1†) reveals a negligible amount of X-ray amorphous lithium carbonate which is most likely due to post-contamination. The impurity level concerning metal ions is fortunately very low as has been verified by EDX (see Fig. S2 $\dagger$ ) and particularly by ICP-MS (see Table S1 in the ESI $\dagger$ ). Altogether, this is a perfect starting condition which helps us to interpret both results from NMR line shape measurements and relaxometry as well as conductivity spectroscopy.

The mean crystallite size of micro- $\mathrm{Li}_{2} \mathrm{O}_{2}$, which is our source material, lies in the $\mu \mathrm{m}$ range as can be seen from the sharp XRD reflections. From the extent of peak broadening we can roughly estimate the mean diameter $\langle d\rangle$ of the crystallites. The well-known equation introduced by Scherrer yields $\langle d\rangle \approx$ $25 \mathrm{~nm}$. This is in good agreement with other oxides which had been treated in high-energy ball mills to produce nanocrystalline ceramics; usually the crystallite sizes are much less than 50 $\mathrm{nm}$ and centre about 10 to $20 \mathrm{~nm} \cdot{ }^{61}$

Unfortunately, nanocrystalline $\mathrm{Li}_{2} \mathrm{O}_{2}$ decomposes at elevated temperatures. Our TG/DSC measurements (see Fig. 2) reveal that oxygen is released at temperatures significantly larger than $493 \mathrm{~K}$. The TG curve is very similar to that reported in ref. 37 . Thus, NMR (and conductivity) measurements (see below) had to be restricted to this limit. Their interpretation needs careful consideration of the thermal stability of nano- $\mathrm{Li}_{2} \mathrm{O}_{2}$, also with respect to grain growth and healing of defects initially introduced.

\section{B. Long-range transport: conductivity measurements and potentiostatic polarization experiments}

1. Conductivity spectroscopy - ionic conduction. Conductivity spectroscopy is able to probe both long-range $(\nu \rightarrow 0)$ as well as short-range ion dynamics. In Fig. 3 conductivity spectra $\sigma^{\prime}(\nu)$, where $\sigma^{\prime}$ is the real part of the complex conductivity $\hat{\sigma}$, of nanocrystalline $\mathrm{Li}_{2} \mathrm{O}_{2}$ are shown which were recorded during heating the sample from $353 \mathrm{~K}$ up to $533 \mathrm{~K}$. They reveal distinct dc plateaus referring to $\sigma^{\prime}(\nu \rightarrow 0) \equiv \sigma_{\mathrm{dc}}$. At lower $T$, a dispersive regime shows up which can be associated with local, i.e., shortranged (forward-backward), jump processes. In many cases, a Jonscher power law, $\sigma^{\prime} \propto \nu^{K}$, is appropriate to account for the frequency dependence of $\sigma^{\prime}$ in this frequency range. The deviation from $\sigma_{\mathrm{dc}}$ in the low-frequency regime is because of polarization effects of the ion-blocking electrodes applied. $\sigma^{\prime}$ in the regime of electrode polarization (EP) often shows a slight change in slope in this frequency range as indicated in Fig. 3(a); the arrow points to the EP flank of the isotherm recorded at $533 \mathrm{~K}$.

At lower $T$ (Fig. 3(b)), the dispersive part starts to dominate the spectra and $\sigma^{\prime}$ tends to obey the relation $\sigma^{\prime} \propto \nu$. This is the signature of nearly-constant-loss (NCL) behavior being typical for complex crystalline and structurally disordered ion conductors, see ref. 62 for an overview on this topic. The behavior $\sigma^{\prime} \propto \nu$ implies a negligible frequency dependence of the dielectric loss, that is the imaginary part of the complex permittivity $\varepsilon^{\prime \prime}(\nu)=\sigma^{\prime}(\nu) /(2 \pi \nu)$ yielding $\sigma_{\mathrm{NCL}}^{\prime}(\nu)=2 \pi \nu \varepsilon_{\mathrm{NCL}}^{\prime \prime}(\nu) \approx$ $A \nu^{1-\alpha}$ with $\alpha>0$ but close to 0 and $A$ being almost independent of $T: \varepsilon_{\mathrm{NCL}}^{\prime \prime}(\nu) 2 \pi \approx A \nu^{-\alpha}$. 
a)

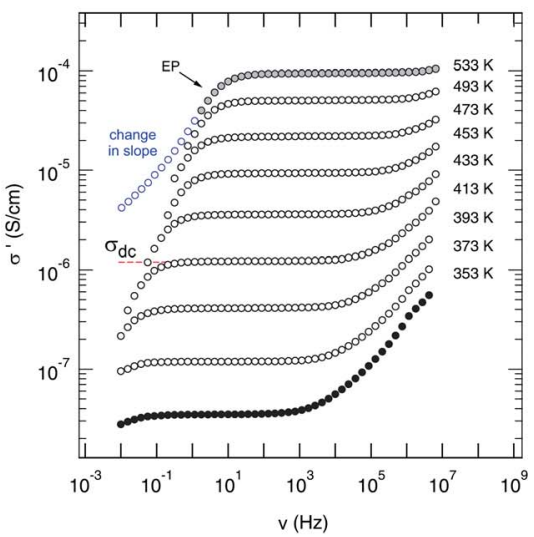

b)

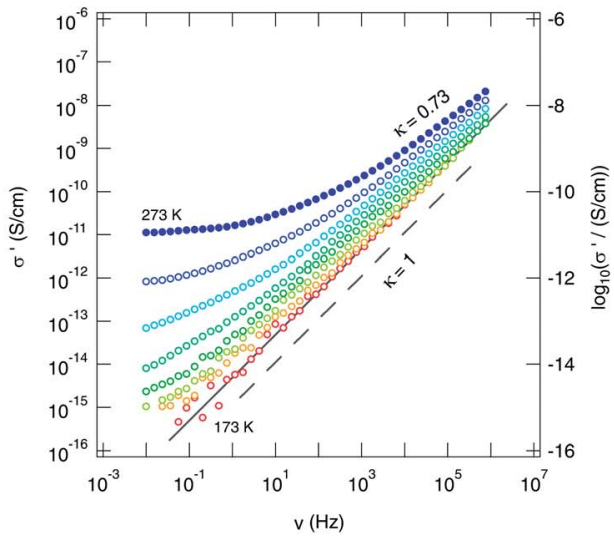

c)

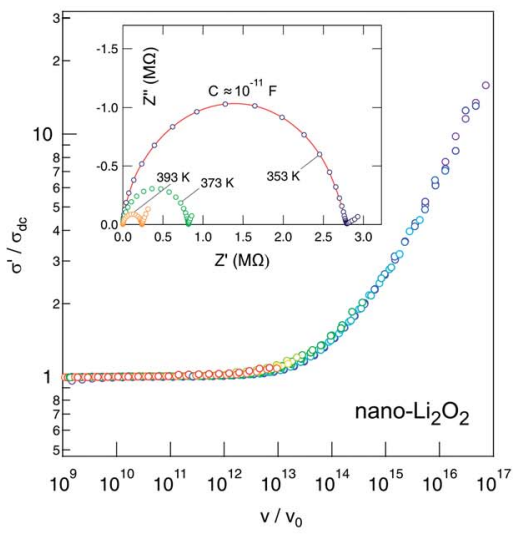

Fig. 3 (a) Conductivity spectra of nanocrystalline $\mathrm{Li}_{2} \mathrm{O}_{2}$ prepared by high-energy ball milling. (b) Conductivity spectra recorded under the same conditions as in (a) but at lower T. $\kappa(=1-\alpha)$ is the Jonscher exponent; a value close to 1 (indicated by the dashed line) points to so-called NCLtype behaviour being frequently interpreted in terms of localized ion motions. The isotherms shown were recorded at $173 \mathrm{~K}, 183 \mathrm{~K}, 193 \mathrm{~K}, 213 \mathrm{~K}$, $233 \mathrm{~K}, 253 \mathrm{~K}$ and $273 \mathrm{~K}$. (c) Scaling of the isotherms shown in (a); the inset shows selected complex plane plots $\left(-Z^{\prime \prime} v s\right.$. $\left.Z^{\prime}\right)$.

NCL behavior is frequently interpreted in terms of strictly localized ion hopping which can be illustrated as caged dynamics in a double-well potential, for example. ${ }^{62}$ The activation energy associated is anticipated to be very small. The electrical response of crystalline $\mathrm{Li}_{2} \mathrm{O}_{2}$ found at low $T$ clearly suggests the presence of NCL-type (ion) dynamics, most probably because of the short distances of possible occupied and unoccupied (interstitial) Li sites within the crystal structure (see Fig. 1).

In contrast to such shallow activated processes, $\sigma_{\mathrm{dc}}$ is sensitive to long-range ion transport usually determined by much higher activation energies being the sum of both the migration enthalpy and the enthalpy needed to form, e.g., vacant Li sites. Siegel and co-coworkers ${ }^{24}$ clearly summarized the types of defects, their equilibrium formation energies and concentrations. As it turned out by first principle calculations, the dominant positively and negatively charged defects are hole polarons and $\mathrm{Li}$ vacancies, respectively. In single crystalline $\mathrm{Li}_{2} \mathrm{O}_{2}$, the formation energies have been calculated to range from 0.93 to $0.95 \mathrm{eV}$ with concentrations in the order of $10^{7} \mathrm{~cm}^{-3}$. $^{24}$

In general, slow $\mathrm{Li}$ ion transport in oxides is characterized by activation energies being much larger than $0.6 \mathrm{eV}^{.63-65} \sigma_{\mathrm{dc}}$ can either be read out from the distinct dc plateaus in Fig. 3(a) or determined by analyzing complex plane plots, which can be constructed when the imaginary part $Z^{\prime \prime}$ of the impedance is plotted as a function of the real part, that is $Z^{\prime}$. An ideal Debye process, governed by an exponential relaxation function, would give a semicircle whose origin coincides with the abscissa. Depressed semicircles, as found for many complex ion conductors showing structural disorder, ${ }^{66}$ directly correlate with the presence of a dispersive part of $\sigma^{\prime}$ and point to a non-Debye response as well as so-called correlated motion. ${ }^{67,68}$ The single semicircles, observed for each temperature here, have to be regarded as a sum of both the response from the bulk and that from the grain boundaries. Electrode effects show up as spikes or tails in the Nyquist plots presented in Fig. 3(c).
Analyzing $-Z^{\prime \prime}\left(Z^{\prime}\right)$ with an appropriate equivalent circuit unit including a resistance and a constant phase element connected in parallel yields a (total) capacity $C$ in the order of $10^{-11} \mathrm{~F}$ (inset of Fig. 3) for the main relaxation process observed. This indicates that, to a major extent, the electrical response, and thus $\sigma_{\mathrm{dc}}$, reflects bulk ion conduction. ${ }^{69}$

The same can be deduced from permittivity spectra $\varepsilon^{\prime}(\nu)$ shown in Fig. 4. While EP shows up once again at low frequencies and high temperatures, the permittivity found at higher frequencies (or lower temperatures) is well below 100 and indicates presumably bulk response. The dashed line in Fig. 4(b) illustrates the permittivity plateau leading to $\varepsilon^{\prime}(0) \approx 30$. This is in line with the value $\left(\varepsilon^{\prime}(0) \approx 35\right)$ which has been reported for microcrystalline $\mathrm{Li}_{2} \mathrm{O}_{2}$ by Gerbig et al. ${ }^{37}$ Moreover, experiments with different electrodes ( $\mathrm{Ti}$ or $\mathrm{Pt}$ ) and ac conductivity measurements as a function of oxygen partial pressure $^{37}$ did not show any indications that oxygen ions determine the overall conductivity. In an $\mathrm{O}_{2}$ atmosphere the incorporation of oxygen consumes electrons leading to the formation of holes that are quite localized corresponding to a superoxide ion $\mathrm{O}_{2}{ }^{-}$on $\mathrm{O}_{2}{ }^{2-}$ sites as electron spin resonance (EPR) spectra had indicated; moreover, the superoxide $\mathrm{O}_{2}{ }^{-}$ anions seem to associate with lithium vacancies. ${ }^{37}$

It is interesting to note that $\varepsilon^{\prime}(0)$ decreases with increasing $T$ although the temperature was still below the decomposition point. Since this process is irreversible, it might reflect the influence of defect healing due to soft sintering of the sample or reflect the smooth onset of $\mathrm{Li}_{2} \mathrm{O}$ release. According to Sidebottom, ${ }^{70}$ and similarly to Roling, ${ }^{71}$ with the help of the Debye model for dipolar relaxation the change in permittivity $\Delta \varepsilon=$ $\varepsilon^{\prime}(0)-\varepsilon^{\prime}(\infty)$ (see Fig. 4) can be related to the number fraction $n^{\prime}$ of the mobile ions and the distance traversed in a single hop. Thus, a slight decrease of $n^{\prime}$, associated with a decrease in ion conductivity $\sigma^{\prime}$ (and consequently $\sigma^{\prime}(\mathrm{dc})$, as presented below), could explain the decrease observed. As pointed out by Ngai and Rendell, ${ }^{72}$ such a decrease could also be interpreted in terms of a change of the underlying motional correlation function. In a 
a)

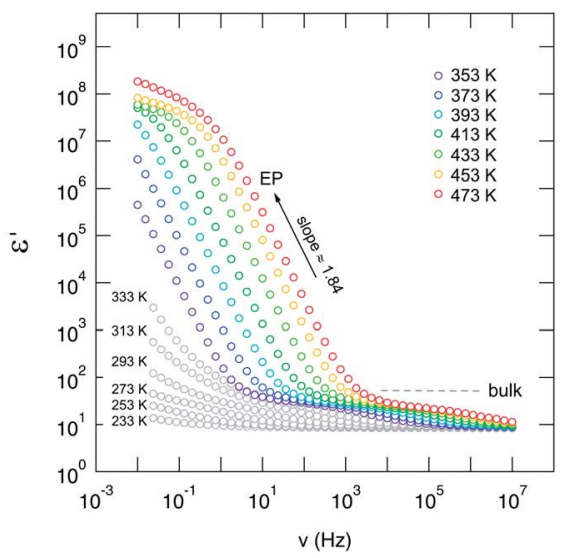

b)

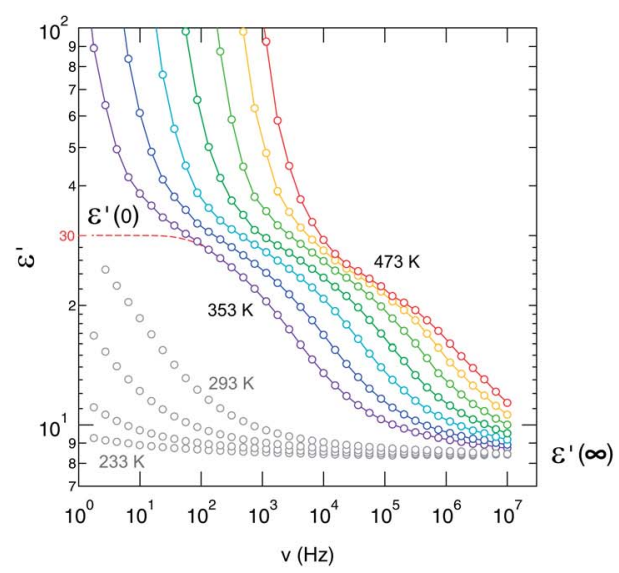

Fig. 4 (a) Permittivity spectra of nanocrystalline $\mathrm{Li}_{2} \mathrm{O}_{2}$ recorded at the temperatures indicated. (b) Magnification of the spectra shown on the left side. Spectra have been recorded in steps of $20 \mathrm{~K} . \varepsilon(0) \approx 30$, which is in good agreement with that deduced for microcrystalline $\mathrm{Li}_{2} \mathrm{O}_{2}$, see ref. 37 , indicates bulk response rather than large contributions from grain boundaries.

wider sense, both interpretations reflect a change of the defect chemistry ${ }^{37}$ in $\mathrm{Li}_{2} \mathrm{O}_{2}$ at elevated $T$ because of the oxygen loss when the sample is exposed to a reducing nitrogen atmosphere.

Despite this slight irreversibility observed, the conductivity spectra $\sigma^{\prime}(\nu)$ recorded up to $450 \mathrm{~K}$ (at least) can be scaled such that they collapse into a single master curve. This means that their shape does not vary significantly with increasing temperature. Here, $\nu_{0}$ (see Fig. 3c) is meant to be the 'characteristic' frequency at which $\sigma^{\prime}=2 \sigma_{\mathrm{dc}}$ holds. This scaling behavior roughly proves that a single (main) charge carrier process seems to be relevant up to $473 \mathrm{~K}$.

Finally, in Fig. $5 \sigma_{\mathrm{dc}} T$, determined from $\sigma^{\prime}(\nu)$, is plotted for micro- and nanocrystalline $\mathrm{Li}_{2} \mathrm{O}_{2}$ as a function of inverse temperature. The arrows mark the conductivities recorded during the heating run and the cooling run, respectively. Heating up to $570 \mathrm{~K}$ has negligible influence on $\sigma_{\mathrm{dc}}$ of the microsample; a much larger influence, however, is observed for nanocrystalline $\mathrm{Li}_{2} \mathrm{O}_{2} \cdot \sigma_{\mathrm{dc}} T$ of the nano-sample starts to deviate from the Arrhenius line drawn if the temperature was raised to $500 \mathrm{~K}$. This temperature is in good agreement with that determined via TG/DSC (see above). Note that between each data point $\left(\sigma_{\mathrm{dc}} T\right)$ the equilibration time to reach a constant temperature was about $20 \mathrm{~min}$. As mentioned above, this feature might be due to $\mathrm{Li}_{2} \mathrm{O}$ release and/or a kind of sintering of the sample. Grain growth and significant sintering, however, could not be observed by XRD.

Most importantly, when comparing the initial conductivities of micro- and nanocrystalline $\mathrm{Li}_{2} \mathrm{O}_{2}$ (heating runs), that of nano$\mathrm{Li}_{2} \mathrm{O}_{2}$ is by more than two orders of magnitude larger than that of micro- $\mathrm{Li}_{2} \mathrm{O}_{2}$. At room temperature we have $\sigma_{\mathrm{dc} \text {,nano }} \approx 1.35 \times$ $10^{-10} \mathrm{~S} \mathrm{~cm}^{-1}$ which corresponds - when the Nernst-Einstein equation is applied - to an overall solid-state diffusion coefficient in the order of $4 \times 10^{-20} \mathrm{~m}^{2} \mathrm{~s}^{-1}$. In accordance with the increase of $\sigma_{\mathrm{dc}}$, the corresponding activation energy for overall (long-range) charge carrier transport is reduced from $E_{\mathrm{a}}=$ $0.88 \mathrm{eV}$ to $0.82 \mathrm{eV}$. This result reflects the influence of crystallite size and structural disorder introduced via ball-milling on macroscopic properties such as overall conductivity, which is the sum of both the electronic and ionic contributions. For comparison, Maier and co-workers, who measured ionic (ion) and electronic (eon) conductivities of microcrystalline $\mathrm{Li}_{2} \mathrm{O}_{2}$, found $E_{\mathrm{a}, \text { ion }}=0.95(5) \mathrm{eV}(423-473 \mathrm{~K})$ and $E_{\mathrm{a} \text {,eon }}=1.3(1) \mathrm{eV}(423-$ $473 \mathrm{~K}$ ), respectively. ${ }^{37}$ The bulk ion conductivity $\sigma_{\text {ion,micro }}$ of $10^{-10}$ to $10^{-9} \mathrm{~S} \mathrm{~cm}^{-1}$ recorded at $373 \mathrm{~K}$ is in perfect agreement with our value of $2 \times 10^{-9} \mathrm{~S} \mathrm{~cm}^{-1}$ (373 K) keeping in mind that the latter represents the total conductivity.

For $\mathrm{Li}_{2} \mathrm{O}_{2}$ which was treated for $1 \mathrm{~h}$ in a Pulverisette 5 mill, Gerbig et al. reported an activation energy being reduced by $\Delta E_{\mathrm{a}}=0.14 \mathrm{eV}$ compared to that of microcrystalline $\mathrm{Li}_{2} \mathrm{O}_{2}$. This result agrees well with our value of $0.82 \mathrm{eV}$. In order to estimate

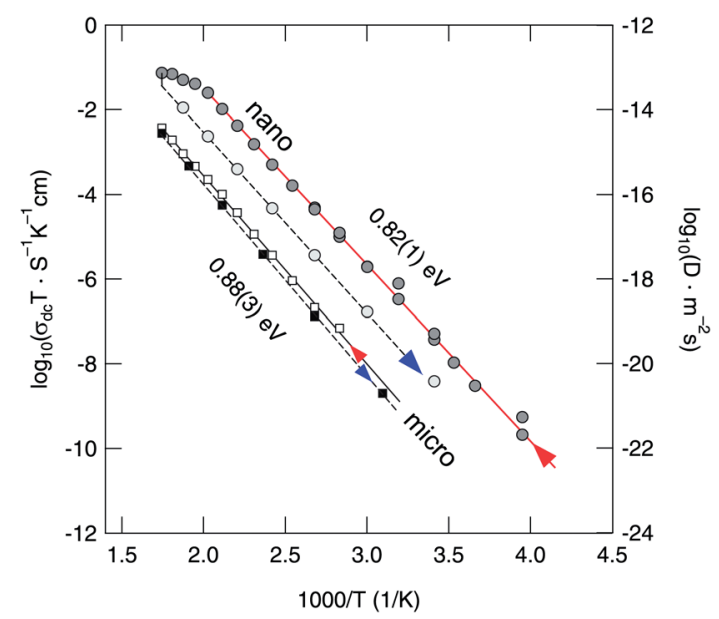

Fig. 5 Arrhenius plot of the total conductivity of nanocrystalline and microcrystalline $\mathrm{Li}_{2} \mathrm{O}_{2}$ measured under a flow of dry nitrogen. The arrows denote the heating and cooling runs, respectively. The activation energies refer to the heating runs. During cooling we obtain $0.90(7) \mathrm{eV}$ (micro) and $0.83(7) \mathrm{eV}$ (nano). To obtain the right axis, $\sigma_{\mathrm{dc}}$ values have been roughly converted into solid-state diffusion coefficients $D$ via the Nernst-Einstein equation. 
any electronic contributions to the total value of $\sigma_{\mathrm{dc}}$, we carried out preliminary potentiostatic polarization measurements at room temperature.

2. Electronic vs. ionic conduction at $293 \mathrm{~K}$. When an ionic conductor is polarized between blocking electrodes, a gold film in this case, the ions will start to migrate. After a while, a concentration gradient is established and the net ionic motion in the electric field stops, the electric field-induced migration being counterbalanced by the chemical back-diffusion of the mobile species. When this stationary state is reached, the residual current is due to electronic conduction only.

The nanocrystalline sample exhibited normal behavior and the current dropped exponentially (see Fig. 6). It has to be noticed that the time needed for stabilization of the current is very long, a fact that indicates a very low conductivity, and thus a very low mobility of the ionic species. Unfortunately, no clear plateau was reached during the experiment. Nevertheless, the electronic conductivity of nano- $\mathrm{Li}_{2} \mathrm{O}_{2}$ is estimated to be approximately $9 \times 10^{-12} \mathrm{~S} \mathrm{~cm}^{-1}$, that is less than $10 \%$ of the total conductivity measured at room temperature $\left(\approx 1.1 \times 10^{-10} \mathrm{~S} \mathrm{~cm}^{-1}\right)$.

In the case of our microcrystalline sample, the conductivity was so low that it was impossible to measure any current at the same polarization voltage $(0.5 \mathrm{~V})$ that was used for the nanocrystalline material. Consequently, the voltage applied was increased tenfold, up to $5 \mathrm{~V}$. Even in this case, it was not possible to see any unequivocal exponential decrease of the current. It has to be noticed that by being submitted to such high voltages, the electrodes will no longer be blocking and there will be no accumulation at the electrode since there is an ongoing chemical reaction. Remarkably, even under such harsh conditions micro$\mathrm{Li}_{2} \mathrm{O}_{2}$ does not show any traces of damage during 1000 hours of the experiment. The conductivity of this sample seems to be extremely low at room temperature. This makes it impossible to measure it in such a direct way with our VMP3 instrument, which is so far limited to measurements at ambient temperature.

Maier and co-workers performed similar measurements but at higher $T$; they were able to exactly determine both $\sigma_{\text {ion }}$ and

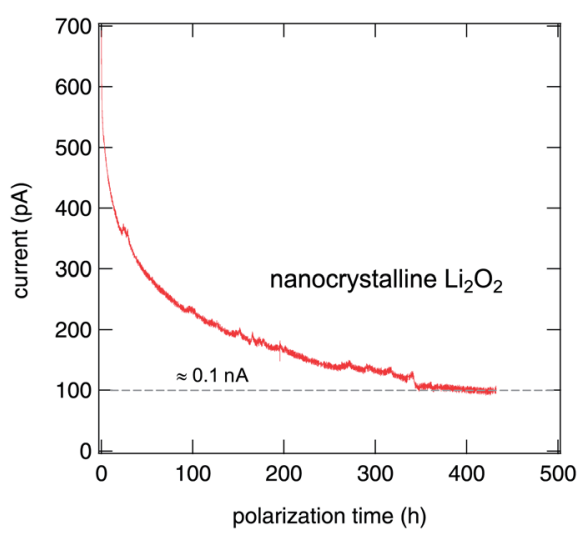

Fig. 6 Polarization curve (dc) of a nanocrystalline lithium peroxide prepared by high-energy ball milling. The electric contact to the pressed-pellet was realized by plasma gold sputtering. The voltage applied across the pellet was $0.5 \mathrm{~V}$. The almost constant current which is reached at long polarization time, that is the (quasi) stationary state, is slightly below 100 pA. $\sigma_{\text {eon }}$ of microcrystalline lithium peroxide. ${ }^{37}$ If we roughly extrapolate their data on micro- $\mathrm{Li}_{2} \mathrm{O}_{2}$ towards room temperature we get $\sigma_{\text {ion }} / \sigma_{\text {eon }} \approx 1000$. The same can be anticipated from our experiments. For our ball-milled sample, however, we found $\sigma_{\text {ion }} / \sigma_{\text {eon }} \approx 10$. This trend is in qualitative agreement with the result reported for nano- $\mathrm{Li}_{2} \mathrm{O}_{2}$, which was, however, only softly milled in a Pulverisette 5 planetary mill for just 1 hour: Gerbig et al. reported on an increase of $\sigma_{\text {ion }}$ by half an order and $\sigma_{\text {eon }}$ by one order of magnitude. ${ }^{37}$ As is well known, the milling conditions, such as the type of mill, the duration of milling, the atmosphere, the ball-to-powder ratio, etc., can drastically influence the structural properties and defect chemistry of the material obtained.

Irrespective of the exact influence of the milling conditions, this comparison reveals that during milling $\sigma_{\text {eon }}$ increases more than $\sigma_{\text {ion }}$ does, leading to a smaller $\sigma_{\text {ion }} / \sigma_{\text {eon }}$ ratio. On the basis of EPR, see ref. 37, the increase of $\sigma_{\text {eon }}$ (measured in an oxygen atmosphere) of a ball-milled sample has been associated with an increasing concentration of superoxide $\mathrm{O}_{2}{ }^{-}$species on peroxide sites corresponding to electron holes.

Before we look in detail on Li jump rates and activation energies deduced from NMR, we shall compare the conductivity results with other ion conductors. Taking into account the electronic contribution to the total conductivity, ion dynamics in nanocrystalline $\mathrm{Li}_{2} \mathrm{O}_{2}$ turned out to be relatively poor. Values of $\sigma_{\text {ion }}$ in the order of $10^{-10} \mathrm{~S} \mathrm{~cm}^{-1}$ and $\sigma_{\text {eon }}$ in the order of $10^{-12}$ $\mathrm{S} \mathrm{cm}^{-1}$ are below those being desired for a lithium-oxygen battery. Preferably, ionic conductivities should be in the order of $10^{-5}$ to $10^{-3} \mathrm{~S} \mathrm{~cm}^{-1}$; electronic ones even two orders of magnitude higher. For comparison, the record holder in terms of extremely good ion conductivity is $\mathrm{Li}_{10} \mathrm{GeP}_{2} \mathrm{~S}_{12}$ with $10^{-3} \mathrm{~S}$ $\mathrm{cm}^{-1}$ at room temperature, ${ }^{75}$ followed by garnet-type oxides ${ }^{42,76}$ $\left(10^{-3} \mathrm{~S} \mathrm{~cm}^{-1}\right.$ at approximately $\left.300 \mathrm{~K}\right)$ or Li-bearing argyrodites. ${ }^{77}$ Activation energies range from 0.35 to $0.25 \mathrm{eV}$. The electronic conductivity of nanocrystalline $\mathrm{Li}_{2} \mathrm{O}_{2}$ prepared by ball-milling is still lower than that of $\mathrm{LiFePO}_{4}\left(10^{-6} \mathrm{~S} \mathrm{~cm}^{-1}\right.$, $0.6 \mathrm{eV}$ (ref. 37 and 78)) that may serve here as a yardstick for a mixed conductor with practical battery applications. In the case of $\mathrm{LiFePO}_{4}$, carbon coating and nanosizing are necessary to prepare an electrode material able to work as a cathode in lithium-ion batteries. Similar conductive coating, however, cannot be realized on the forming/disappearing $\mathrm{Li}_{2} \mathrm{O}_{2}$; the electronic conductivity values not to be rate limiting would have to be again several orders of magnitude higher. This might be achieved by further doping of the material as well as further introduction of structural disorder. ${ }^{36}$ Taking advantage of nontrivial nano-size effects would lead to the question how does ion conductivity depend on the size of the crystallites? This would require a systematic study which is beyond the scope of the present investigation focussing on the elementary steps of hopping in ball-milled $\mathrm{Li}_{2} \mathrm{O}_{2}$.

\section{Short-range motions: NMR spectra and relaxation rates}

Temperature-variable ${ }^{7} \mathrm{Li}$ NMR spectra, when recorded under static, i.e., non-rotating conditions, are sensitive to $\mathrm{Li}$ ion hopping processes. ${ }^{79-83}$ In Fig. $7{ }^{7} \mathrm{Li}$ NMR spectra of both micro- 
and nano-crystalline $\mathrm{Li}_{2} \mathrm{O}_{2}$ are shown. Although ${ }^{7} \mathrm{Li}$ is a quadrupole nucleus, due to symmetry reasons there is no electric field gradient present at the Li sites which would lead to a so-called quadruple powder pattern. ${ }^{73}$ At sufficiently low temperature the NMR line is dipolarly broadened and its shape is similar to a Gaussian. For comparison, the corresponding rigid-lattice $\mathrm{Li}$ NMR spectrum of $\mathrm{Li}_{2} \mathrm{O}$, crystallizing with cubic symmetry, looks very similar. ${ }^{74,84}$ At temperatures below ambience, the Li hopping rate $1 / \tau$ is low and does not affect the spectra. With increasing temperature, however, $1 / \tau$ increases and causes line narrowing. If $1 / \tau$ reaches the value of the NMR line width, which is $17.5 \mathrm{kHz}$ at $290 \mathrm{~K}$, homonuclear dipoledipole interactions governing the line in the rigid lattice regime become increasingly averaged. In the present case, the so-called motional narrowing clearly proceeds in a heterogenous way which means that a narrow NMR line emerges at elevated $T$ and superimposes the broad one..$^{74,84,85}$ The spectrum of micro- $\mathrm{Li}_{2} \mathrm{O}_{2}$ reveals that this process starts at around $482 \mathrm{~K}$; it can be even better recognized when the spectrum recorded at $604 \mathrm{~K}$ is regarded.

Importantly, in the case of nanocrystalline $\mathrm{Li}_{2} \mathrm{O}_{2}$ the same process occurs, however, it starts at significantly lower temperatures. For comparison, at $355 \mathrm{~K}$ the two dynamically different spin reservoirs can be well differentiated from each other while the corresponding spectra of the microcrystalline sample still show the broad Gaussian-shaped line. Regarding previous studies on nanocrystalline $\mathrm{Li}_{2} \mathrm{O}$ by Heitjans and coworkers ${ }^{85,86}$ such two-component NMR line shapes have been interpreted in terms of (mobile) Li spins residing in or near the large volume fraction of interfacial regions generated during milling. ${ }^{74,85}$ This assignment can also be adapted to explain the spectra of nano- $\mathrm{Li}_{2} \mathrm{O}_{2}$, which is anticipated to be characterized by a large number fraction of defects. Since the feature of a twocomponent line shape did also show up for micro- $\mathrm{Li}_{2} \mathrm{O}_{2}$ at elevated temperatures, the emergence of a narrow NMR line is either connected to thermally induced defects, formed also in micro- $\mathrm{Li}_{2} \mathrm{O}_{2}$, or to an intrinsic heterogeneous $\mathrm{Li}^{+}$dynamics in the peroxide.

It is worth noting that the heterogenous narrowing shown in Fig. 7 for nanocrystalline $\mathrm{Li}_{2} \mathrm{O}_{2}$ is fully reversible. The irreversible decomposition into $\mathrm{Li}_{2} \mathrm{O}$, which smoothly starts above $500 \mathrm{~K}$ according to TG/DSC and which could also have its microscopic (atomic-scale) infancy at $473 \mathrm{~K}$, cannot be used to explain the two-component behavior observed. Here, we believe that its origin is almost completely related to the mechanically induced defect-rich structure formed. The area fraction $A_{\mathrm{f}}$ of the narrow NMR component as well as the evolution of the widths of the two NMR lines of nano- $\mathrm{Li}_{2} \mathrm{O}_{2}$ are shown in Fig. 8.

Starting from approximately $18 \mathrm{kHz}$ the broad component slightly decreases. The motionally narrowed NMR line shows up at elevated $T$; its width is $1.7(1) \mathrm{kHz}$. $A_{\mathrm{f}}$ reaches $5 \%$ at $450 \mathrm{~K}$, thus, indicating that only a small number fraction of $\mathrm{Li}$ ions is involved in the fast diffusion process. $A_{\mathrm{f}}$ corresponds to the area fraction of that component of the FIDs which after Fourier transformation yields a narrowed NMR line. In Fig. 9, two FIDs of a spin-locking $R_{1 \rho}$ experiment $(28 \mathrm{kHz})$ are shown, which have been recorded at quite different temperatures, viz. $233 \mathrm{~K}$ and $455 \mathrm{~K}$. While in both cases the fast decaying part corresponds to the broad Gaussian obtained after Fourier transformation, only the FID recorded at $455 \mathrm{~K}$ reveals an additional intensity slowly decaying with acquisition time, see also ref. 84 . Before we briefly discuss the separate analysis of this slowly
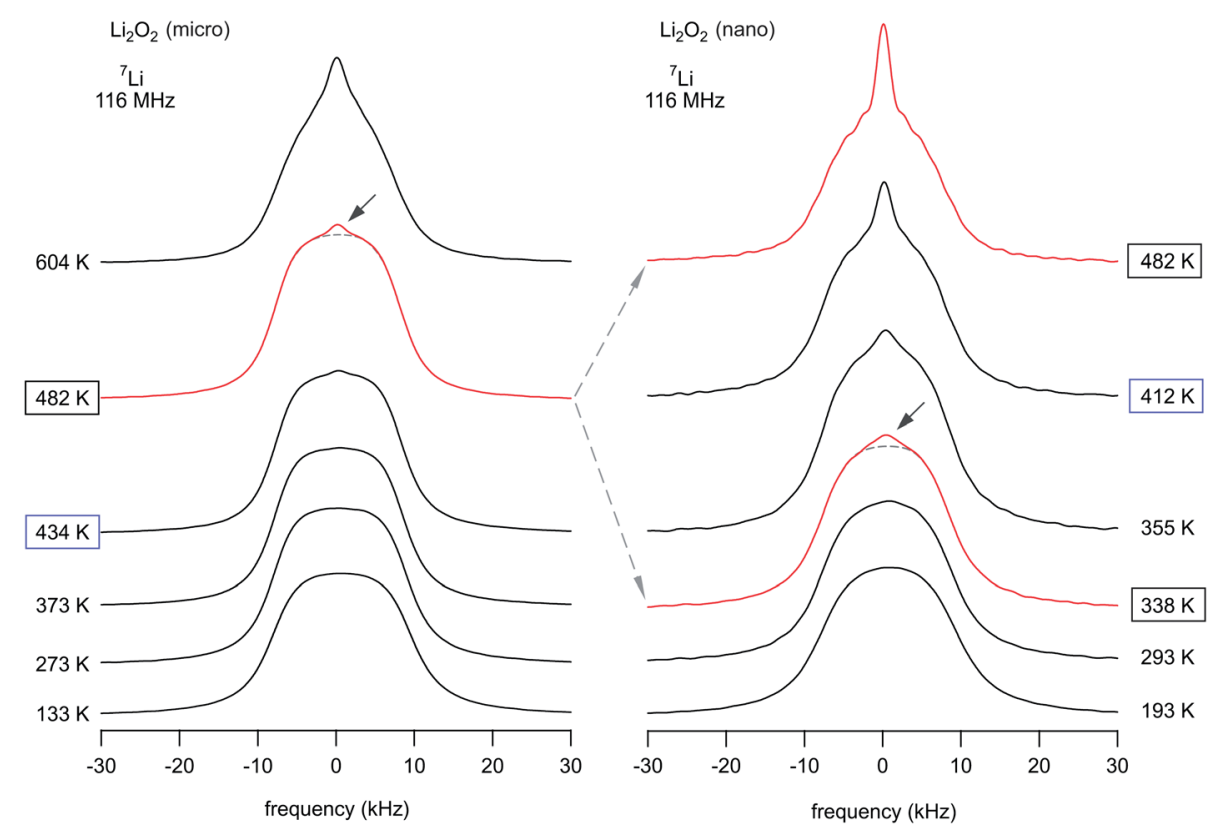

Fig. 7 Static ${ }^{7} \mathrm{Li} \mathrm{NMR}$ spectra of microcrystalline (left) and nanocrystalline (right) $\mathrm{Li}_{2} \mathrm{O}_{2}$ recorded at $116 \mathrm{MHz}$ and at the temperatures indicated. The arrows indicate a motionally narrowed NMR line superimposing the broad line, being characteristic for $\mathrm{Li}_{\text {ions in }} \mathrm{microcrystalline} \mathrm{Li}_{2} \mathrm{O}_{2}$. Since the electric field gradient at the $\mathrm{Li}$ sites in $\mathrm{Li}_{2} \mathrm{O}_{2}$ vanishes due to symmetry reasons, ${ }^{7} \mathrm{Li}$ NMR spectra of $\mathrm{Li}_{2} \mathrm{O}_{2}$ are composed of a single line (the 'central' line) only, see also ref. 73. The same situation was found, e.g., for $\mathrm{Li}_{2} \mathrm{O}$ with perfect cubic symmetry. ${ }^{74}$ 


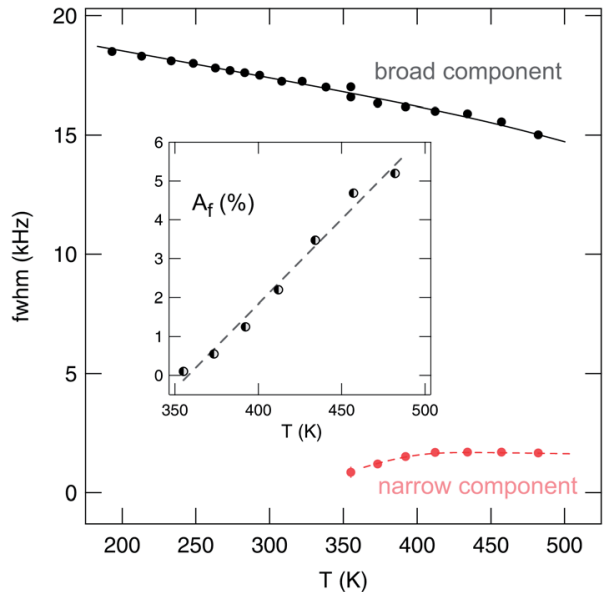

Fig. 8 Line widths (fwhm, full width at half maximum) of the two NMR components visible in the ${ }^{7} \mathrm{Li}$ NMR spectra shown in Fig. 7. $A_{f}$ denotes the area fraction, which also equals the number fraction, of fast diffusing Li spins in nanocrystalline lithium peroxide prepared by highenergy ball milling.

decaying part in the frame of a spin-locking NMR experiment, which is certainly limited because of the low intensity of this contribution, we firstly present the rates $R_{1}$ and $R_{1 \rho}$, which can be deduced from the FIDs when the whole area under the curve is evaluated as a function of waiting or locking time.

As an example, in Fig. 10 selected magnetization transients of our spin-lock experiments are shown. They quantify the transversal decay of $M_{\mathrm{Q}}\left(t_{\text {lock }}\right)$ according to $M_{\mathrm{Q}}\left(t_{\text {lock }}\right) \propto$ $\exp \left(-\left(t_{\text {lock }} / T_{1 \mathrm{Q}}\right)^{\gamma_{\mathrm{e}}}\right) \cdot \gamma_{\mathrm{Q}}(T)$ is shown in Fig. 11. Over the whole temperature range the transients can be best fitted with stretched exponentials; a separation of the two spin reservoirs discussed above, e.g., by the use of two single exponentials, is hardly possible because of the low number fraction of fast relaxing spins. Therefore, the rates shown in Fig. 11, which gives an overview of the NMR rates (and stretching exponents $\gamma$ )

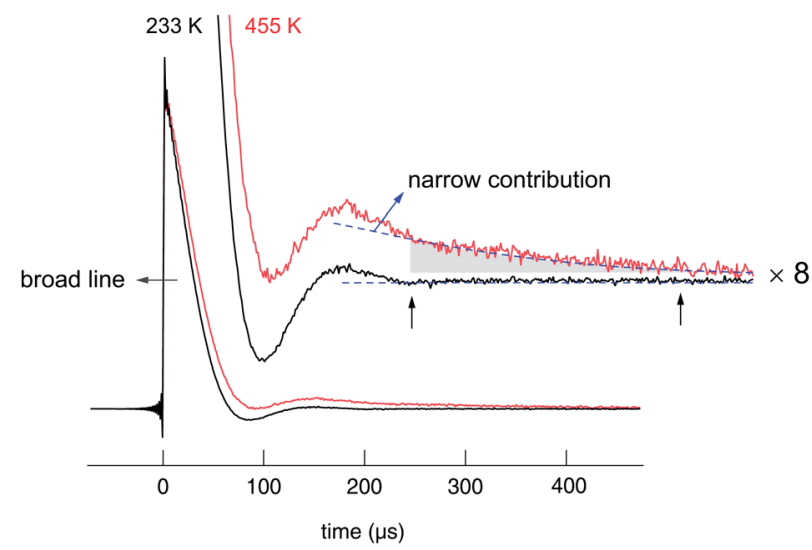

Fig. $9{ }^{7} \mathrm{Li}$ NMR (transversal) transients of nanocrystalline $\mathrm{Li}_{2} \mathrm{O}_{2}$ recorded by the spin-lock technique at $28 \mathrm{kHz}$ and a Larmor frequency of $116 \mathrm{MHz}$. In contrast to the signal recorded at $233 \mathrm{~K}$, the FID obtained at elevated $T$ reveals a slowly decaying intensity, which is responsible for the motionally narrowed NMR line visible in the Fourier transforms in Fig. 7. of the nano- $\mathrm{Li}_{2} \mathrm{O}_{2}$ measured, represent those ions which are not directly responsible for the motionally narrowed NMR line detected. The observation that the $R_{1 \rho}$ transients can only be fitted with stretched exponentials rather than with a single exponential might be connected to the fact that non-exponential curves can be expected for ${ }^{7} \mathrm{Li}$; this can be due to intrinsic as well as extrinsic reasons: (i) as a spin-3/2 nucleus ${ }^{7} \mathrm{Li}$ interacts with electric field gradients being associated with defects introduced, (ii) the interaction with paramagnetic impurities may also lead to such a behavior, and/or (iii) independent of such extrinsic influences the underlying hopping correlation function could be of non-exponential shape from the outset. If not being an intrinsic feature of a single ion hopping process in nanocrystalline $\mathrm{Li}_{2} \mathrm{O}_{2}$, the latter could also be the result of heterogeneous dynamics, i.e., the overall dynamics observed is the result of a superposition of many jump processes each being describable by single exponential motional correlation functions. The latter might be corroborated by the observation that at least $\gamma$ of our $R_{1 \rho}$ transients varies with temperature. This points to a shift of Li dynamics in favor of an overall (nonexponential) diffusion process. Such a process increasingly may become governed by correlated motion either due to structural disorder or repulsive (Coulomb) interactions of the jumping ions.

Compared to the corresponding $\gamma$ values of microcrystalline $\mathrm{Li}_{2} \mathrm{O}_{2}$, which vary, over the temperature range covered, from 0.84 to $0.72\left(R_{1}\right)$ and from 0.64 to $0.44\left(R_{1 \rho}\right)$, the results indicate that ball-milling shifts $\gamma$ of $R_{1}$ towards values closer to one rather than affecting the stretching exponents in the opposite direction. At least, this is valid for the so-called non-diffusive temperature regime which in the case of $R_{1 \rho}$ becomes apparent below $200 \mathrm{~K}$. For comparison, in the temperature regime covered here, the $R_{1}$ rates are clearly not induced by translational Li diffusion; even up to $500 \mathrm{~K}$ only a non-diffusive background rate is detected which does only weakly depend on $T$. This can be easily explained by the different sensitivities of the two methods to Li diffusivity. ${ }^{40,87}$ While $R_{1 \rho}$ measurements do probe Li dynamics with jump rates in the order of the locking

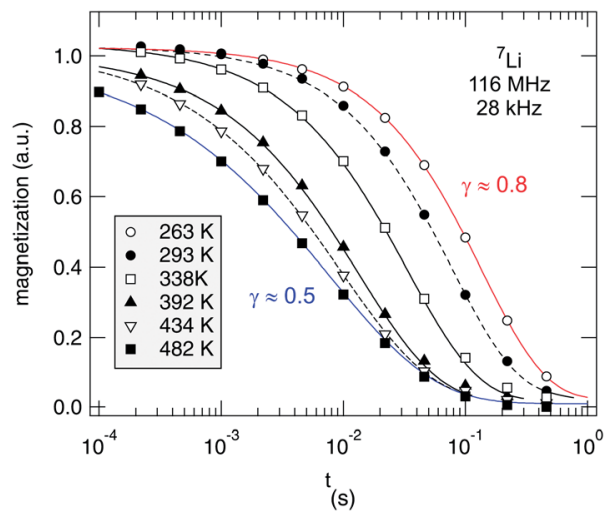

Fig. 10 Temperature-variable ${ }^{7} \mathrm{Li}$ NMR $R_{1 \rho}$ transients recorded in the rotating frame using a spin-locking frequency of $28 \mathrm{kHz}$. Solid and dashed lines show fits with stretched exponentials. The stretching exponents $\gamma_{e}$ are shown as a function of $T$ in Fig. 10. 
a)

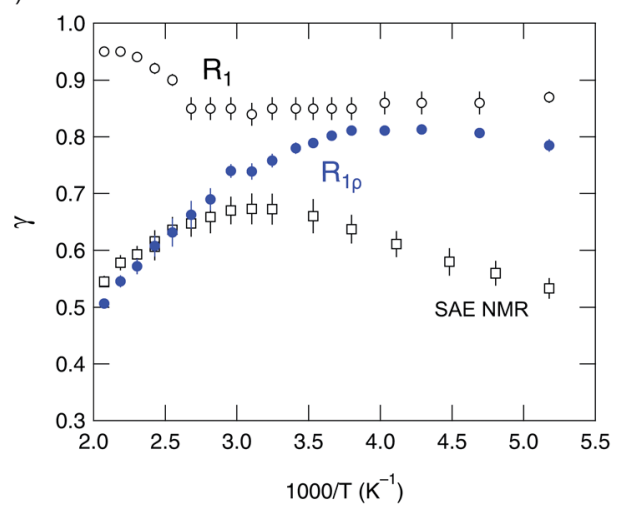

b)

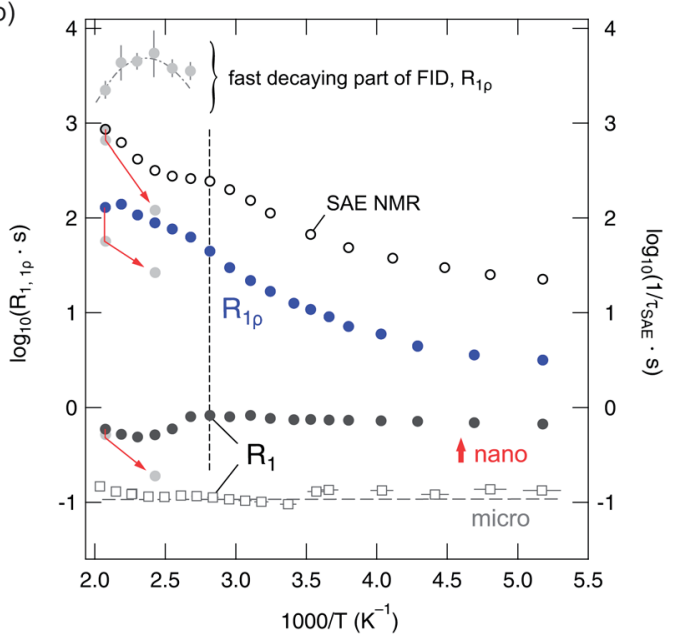

Fig. 11 (a) Stretching factors $\gamma_{(\rho)}$ used to parameterize the various magnetization transients $\left(R_{1}, R_{1 \rho}\right)$ and echo decay curves (SAE NMR) of nano- $\mathrm{Li}_{2} \mathrm{O}_{2}$. (b) Arrhenius plot of the ${ }^{7} \mathrm{Li} \mathrm{NMR}$ relaxation rates of nanocrystalline $\mathrm{Li}_{2} \mathrm{O}_{2}$ measured. The rates shown were obtained by analysing the magnetization transients and echo damping curves with stretched exponentials. The data were acquired at $116 \mathrm{MHz}$ and at a locking frequency of $\omega_{1} / 2 \pi=28 \mathrm{kHz}$. For comparison, the $R_{1}$ rates of microcrystalline $\mathrm{Li}_{2} \mathrm{O}_{2}$ are also shown. The arrows point to those rates which were recorded during cooling.

frequency, that is, $28 \mathrm{kHz}$ in our case, $R_{1}$ is, however, sensitive to jumps with rates on the $\mathrm{MHz}$ time-scale. The latter is defined by the Larmor frequency itself.

It is worth mentioning that the $R_{1}$ rates apparently show a shallow local minimum around $430 \mathrm{~K}$. In the same temperature regime, steps in $R_{1 \rho}(1 / T)$ (and $\tau_{\mathrm{SAE}}^{-1}(1 / T)$ ) show up (see Fig. 12). These might be related to variations in the diffusion mechanism and/or slight structural changes. The observations will be discussed in more detail below. When analyzing the low- $T$ flanks of diffusion-induced NMR rate peaks, we expect activation energies being much smaller than those probed by conductivity spectroscopy in the de limit. This is simply due to the fact that in the low- $T$ limit, NMR relaxometry is in general sensitive to the local jump process rather than to long-range ion transport. This has been recently outlined by our group on a fluorine anion conductor. ${ }^{88}$ Here, we use the results from NMR to make comparisons with recent theoretical predictions about local hopping barriers.
For this purpose and for further analysis of our data, it is important to emphasize that the poor ion conductivity probed expectedly manifests itself in the observation that only the rate $R_{1 \rho}$ is able to probe Li dynamics below $500 \mathrm{~K}$. This also holds for the SAE NMR measurements, which reveal a diffusion-induced contribution at elevated temperatures. To separate the influence of non-diffusive and weaker-than-activated background effects on the (purely) diffusion-induced rates $R_{1 \rho}$ and $\tau_{\mathrm{SAE}}^{-1}$, we parameterized the low-temperature background rates with appropriate power laws $R_{1 \rho} \propto T^{\beta}$. An extrapolation to higher temperatures allowed for calculating the desired diffusioninduced $R_{1 \rho \text {,diff }}$ rates (see unfilled symbols in Fig. 12(a) and (b)). After this correction procedure, $R_{1 \rho \text {,diff }}(1 / T)$ of microcrystalline $\mathrm{Li}_{2} \mathrm{O}_{2}$ reveals a low-temperature flank pointing to a (low- $T$ ) activation energy of $0.30 \mathrm{eV}$ (Fig. 12(a)). This is in good agreement with calculated hopping barriers for negatively charged $\mathrm{Li}$ vacancies (0.33-0.39 eV) by Radin et $a .^{24}$ and Hummelshøj et $a l .{ }^{32,33}$ The calculations of Radin and Siegel reveal that the lowest energy pathway $(0.33 \mathrm{eV})$ corresponds to migration between adjacent octahedral sites. ${ }^{24}$

At elevated temperatures, that is at $430 \mathrm{~K}$, the NMR rates reach a plateau value. If not associated with slight microstructural changes of the material, which are not detectable via XRD, it might be related to a shallow local rate maximum. Since no substantial NMR line narrowing shows up, this, however, can only be an indication of localized, i.e., strictly short-ranged $\mathrm{Li}$ motions between adjacent energy minima in the structure of the peroxide. As mentioned above, such localized motions appear as $\varepsilon^{\prime \prime} \neq f(\nu)\left(\right.$ or $\left.\sigma^{\prime} \propto \nu\right)$ in conductivity spectroscopy. With increasing temperature, the rates increase further and follow an Arrhenius line with an activation energy of $0.47 \mathrm{eV}$ (Fig. 12(a)). Interestingly, this value is in agreement with that proposed for the binding or interaction energy between hole polarons and lithium vacancies $(0.47 \mathrm{eV}) .{ }^{34}$ As we will see below, a somewhat smaller activation energy was found by SAE NMR in this region $(0.41 \mathrm{eV})$, which is in agreement with the first-principle calculations of Radin and Siegel for nearest neighbor hole polaron hopping $(0.42 \mathrm{eV}) .{ }^{24}$ For comparison, the model used by Luntz et al., for example, points to $0.38 \mathrm{eV}^{27}$ Hence, it cannot be excluded that also polaron dynamics can be indirectly seen by ${ }^{7} \mathrm{Li}$ NMR. When comparing these values we have to keep in mind, however, that the involvement of trigonal prismatic sites in Li dynamics leads to a barrier of $0.39 \mathrm{eV}^{24}$

Even after a generous background correction, the corresponding rates of the nanocrystalline sample are shifted towards larger values (see Fig. 12(b)) and follow an Arrhenius law as determined by a smaller activation energy of only $0.22 \mathrm{eV}$. As in the case of the microcrystalline sample, a discontinuity is observed. It shows up at $400 \mathrm{~K}$ and is most likely of the same origin as discussed for the non-treated sample. For comparison, in the case of $\tau_{\mathrm{SAE}}^{-1}$ of nano- $\mathrm{Li}_{2} \mathrm{O}_{2}$ (see Fig. 12(c)) it is shifted towards even lower temperatures $(360 \mathrm{~K})$. The activation energy turned out to be slightly larger than that probed via the spinlock NMR technique. Altogether, the shift of the relaxation and decay rates observed for the sample mechanically treated indicates enhanced local Li hopping as compared to the starting material, which has also been observed for nanocrystalline 
a)

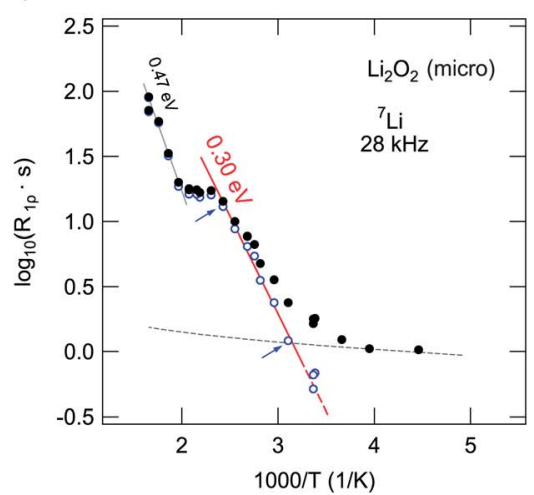

b)

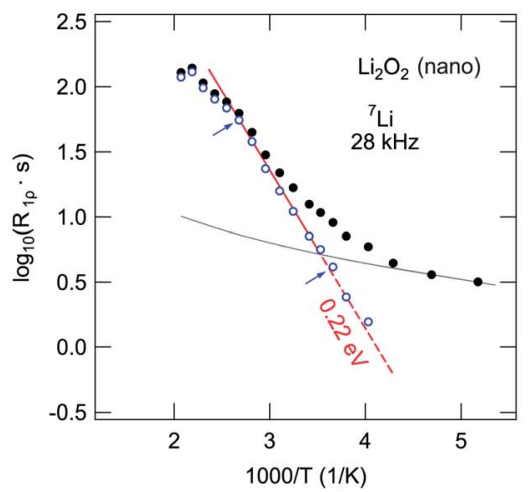

c)

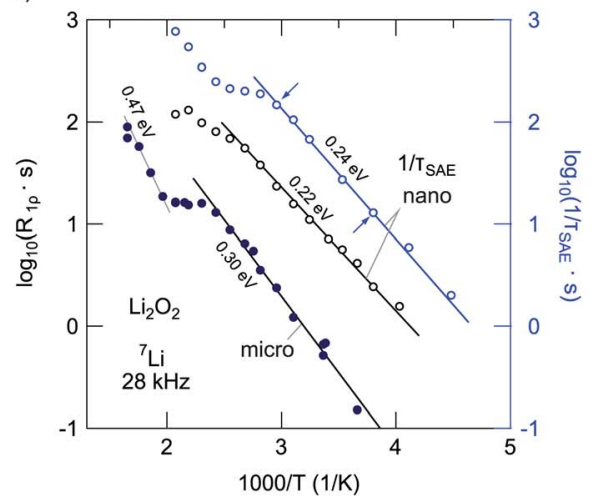

Fig. 12 (a) and (b) ${ }^{7} \mathrm{Li}$ spin-lattice relaxation rates $\left(116 \mathrm{MHz}, 28 \mathrm{kHz}\right.$ locking frequency) of micro- and nanocrystalline $\mathrm{Li}_{2} \mathrm{O}_{2}$ as a function of inverse temperature. The dashed lines correspond to power laws characterizing the non-diffusive background contributions to the overall rates. The correction procedure to obtain SLR rates mainly induced by diffusion is described in the text; solid lines represent Arrhenius fits, the activation energies obtained are indicated. Arrows mark the fitting ranges. (c) Comparison of the ${ }^{7}$ Li SLR NMR rates recorded in the rotating frame of reference with those obtained from SAE NMR for nano- $\mathrm{Li}_{2} \mathrm{O}_{2}$.

$\mathrm{Li}_{2} \mathrm{O}^{74,85}$ and other ion conductors prepared by milling. ${ }^{63,79,89-92}$ As in the case of $R_{1}$ of micro- $\mathrm{Li}_{2} \mathrm{O}_{2}$, above $400 \mathrm{~K}$ the rates $\tau_{\mathrm{SAE}}^{-1}$ increase further; the corresponding activation energy is approximately $0.42 \mathrm{eV}$ (as already mentioned above).

Let us point out that the difference between $R_{1 \rho}$ and $\tau_{\text {SAE }}^{-1}$ of nano-Li $\mathrm{L}_{2} \mathrm{O}_{2}$ likely reflects the increased sensitivity of SAE NMR to very slow $\mathrm{Li}$ exchange processes..$^{55,87,93-99}$ These might be found in the crystalline cores of the nanostructured sample. Indeed, the shape of the curve $\tau_{\mathrm{SAE}}^{-1}(1 / T)$ resembles that of $R_{1 \rho}(1 / T)$ of micro- $\mathrm{Li}_{2} \mathrm{O}_{2}$. In the present case, we tend to interpret the SAE decay rates as dipolar relaxation rates rather than taking them as real jump rates. The latter has been found for a variety of materials with Li migration pathways being formed by multiple electrically inequivalent Li sites. ${ }^{87}$ Because of both the small activation energy found by SAE NMR and the low preexponential factor associated, we thus suspect that dipoledipole interactions strongly influence the spin-alignment echo damping and hence govern the decay rates obtained. Furthermore, at the lowest temperatures $\tau_{\mathrm{SAE}}^{-1}$ seems to be increasingly influenced by spin-diffusion, which hampers the detection of echo damping that is (purely) induced by particle diffusion.

Mechanical treatment has also an effect on the background rates measured by the various NMR techniques applied. For both $R_{1}$ and $R_{1 \rho}$ we observed an increase of the non-diffusion induced rates by one order of magnitude. Several phenomena could serve as origins for this observation such as (i) strictly localized motions, as characterized by an NCL effect (vide supra), (ii) coupling of spins to unpaired electrons, or (iii) a change of lattice vibrations. The increasing concentration of electron holes observed by Gerbig and co-workers ${ }^{37}$ might be useful to explain such differences observed for ball-milled $\mathrm{Li}_{2} \mathrm{O}_{2}$.

Taken together, enhanced long-range ion transport, as evidenced by conductivity spectroscopy, is also accompanied by increased short-range motions of all of the ${ }^{7} \mathrm{Li}$ NMR spins. This is reflected by decreased activation energies and increased (diffusion-induced) overall relaxation rates. Importantly, the latter shows increased $\mathrm{Li}$ ion dynamics even in the bulk of $\mathrm{Li}_{2} \mathrm{O}_{2}$ nanocrystallites. To detail the fast ${ }^{7} \mathrm{Li}$ spin reservoir as seen via NMR line shapes, let us reconsider the two-component line shape and the associated FIDs of nanocrystalline $\mathrm{Li}_{2} \mathrm{O}_{2}$ at elevated $T$ in a quantitative way. If we integrate only the slowly decaying part of the FID, it should be possible to separate the ions which are responsible for the narrowed line from those reflected by the broad one.

In Fig. 9 the two vertically drawn arrows indicate the integration range that we used to construct the corresponding temperature-variable magnetization transients. For comparison, in Fig. 11(b) the SLR rates obtained are shown as grey circles in the upper part of the Arrhenius diagram. Their temperature dependence might be interpreted as a shallow maximum since the rates indeed start to decrease with increasing temperature. With the maximum condition valid for a $R_{1 \rho}(1 / T)$-peak, $\omega_{1} \tau_{\mathrm{c}} \approx 0.5$, we obtained a motional correlation rate of $\tau_{\mathrm{c}}^{-1}=3.5 \times 10^{5} \mathrm{~s}^{-1}$ at $473 \mathrm{~K}$. Within a factor of two the correlation time $\tau_{\mathrm{c}}$ is expected to be equal to the Li residence time between two successful jumps. Assuming a mean jump distance of only $2.5 \AA$, the Einstein-Smoluchowski equation for $3 \mathrm{D}$ uncorrelated motion ${ }^{100}$ yields a self-diffusion coefficient $D$ in the order of $D(473 \mathrm{~K})=1 \times 10^{-14} \mathrm{~m}^{2} \mathrm{~s}^{-1}$. For comparison with conductivity spectroscopy, a diffusion coefficient within this order is in good agreement with $2.1 \times 10^{-5} \mathrm{~S} \mathrm{~cm}^{-1}$ as probed at the same temperature. This agreement points out that ion transport to which $\sigma_{\mathrm{dc}}$ is sensitive seems to be mainly governed by the fast Li sub-ensemble detected by NMR. This Li reservoir could be a spatially local one near or in the surface-influenced interfacial regions of the nm sized, structurally disordered $\mathrm{Li}_{2} \mathrm{O}_{2}$ crystallites. ${ }^{74,85}$ It might be comparable to that expected for $\mathrm{Li}$ ion surface diffusion.

For comparison with other Li ion conductors, both active materials and solid electrolytes, a diffusion coefficient in the order of $D(473 \mathrm{~K})=1 \times 10^{-14} \mathrm{~m}^{2} \mathrm{~s}^{-1}$ reflects rather poor ion diffusivity. Considering recent examples that have been investigated by NMR, Li-bearing argyrodite, $\mathrm{Li}_{6} \mathrm{PSe}_{5} \mathrm{Br}$, shows values 
as high as $10^{-12} \mathrm{~m}^{2} \mathrm{~s}^{-1}$ at $263 \mathrm{~K}^{.83} \mathrm{Li}$ diffusion in the anode material $\mathrm{LiC}_{6}$ is in the order of $10^{-15} \mathrm{~m}^{2} \mathrm{~s}^{-1}$ at $300 \mathrm{~K}$, while we have $4 \times 10^{-20} \mathrm{~m}^{2} \mathrm{~s}^{-1}$ in the case of nano- $\mathrm{Li}_{2} \mathrm{O}_{2}$ (see Fig. 5). ${ }^{82} \mathrm{In}$ addition, the well-known garnet-type electrolyte, Al-doped $\mathrm{Li}_{7} \mathrm{Zr}_{2} \mathrm{La}_{3} \mathrm{O}_{12}$, shows a $D$ value of $10^{-14} \mathrm{~m}^{2} \mathrm{~s}^{-1}$ at ambient temperature rather than at $473 \mathrm{~K}$; the corresponding activation energy is much lower and turned out to be $0.35 \mathrm{eV}^{42}$ Interestingly, quite recently, Siegel and co-workers ${ }^{36}$ calculated the ionic conductivity for amorphous $\mathrm{Li}_{2} \mathrm{O}_{2}$ and found enhanced dynamics characterized by $10^{-7} \mathrm{~S} \mathrm{~cm}^{-1}$. This is three orders of magnitude larger than that for nanocrystalline $\mathrm{Li}_{2} \mathrm{O}_{2}$ prepared by ball milling.

Considering electronic properties, quite recently, Geng et al. ${ }^{101}$ have employed first-principles density functional theory calculations to study the properties of gain boundaries in $\mathrm{Li}_{2} \mathrm{O}_{2}$. They report on electronic conduction channels in polycrystalline $\mathrm{Li}_{2} \mathrm{O}_{2}$ opened up by stable grain boundaries. Considering also space charge effects, which are known to influence both ionic and electronic charge carrier transport, ${ }^{\mathbf{1 0 2 - 1 0 5}}$ it underpins the important role of interfaces to be considered when dynamic properties shall be engineered, see also ref. 5 .

\section{Summary and conclusions}

Charge carrier transport and $\mathrm{Li}$ ion dynamics of nanocrystalline lithium peroxide were investigated by the complementary techniques of conductivity and NMR spectroscopy. In agreement with the recent study by Gerbig et al. translational Li ion dynamics as well as electron transport turned out to be rather poor in microcrystalline $\mathrm{Li}_{2} \mathrm{O}_{2}$. After high-energy ball milling, however, the overall conductivity has been increased by more than two orders of magnitude and reaches $1.1 \times 10^{-10} \mathrm{~S} \mathrm{~cm}^{-1}$ at room temperature. Potentiostatic polarization measurements reveal a discernable electronic contribution (approximately $10 \%)$ to the total conductivity. Compared to the non-milled starting material, the activation energy decreased from $0.88 \mathrm{eV}$ to $0.82 \mathrm{eV}$.

While at very low temperatures the nearly constant loss phenomenon leaves its fingerprints in the frequency dependence of the conductivity $\sigma^{\prime}$, above $250 \mathrm{~K}$ the ${ }^{7} \mathrm{Li}$ NMR relaxometry measurements on nano- $\mathrm{Li}_{2} \mathrm{O}_{2}$ point to sort-range motions with an activation energy of approximately $0.22 \mathrm{eV}$. In a similar way, this is also observed for microcrystalline lithium peroxide, the activation energy, however, is somewhat larger $(0.30 \mathrm{eV})$. Most importantly, well below the decomposition range of nanocrystalline $\mathrm{Li}_{2} \mathrm{O}_{2}$, the static ${ }^{7} \mathrm{Li}$ NMR line shapes are composed of two components. While the broad one is identical to that observed for micro $\mathrm{Li}_{2} \mathrm{O}_{2}$, the motionally narrowed line represents a sub-ensemble of relatively fast $\mathrm{Li}$ ions. Analyzing this component in the frame of a $T_{1 \rho}$ NMR experiment - to the best of our knowledge such a separation has not been reported so far for $R_{1 \rho}$ rates - we were able to roughly estimate the corresponding Li jump rate at $473 \mathrm{~K}$ and, hence, the self-diffusion coefficient. The latter, which is in the order of $10^{-14} \mathrm{~m}^{2} \mathrm{~s}^{-1}$, corresponds well with the dc conductivity probed at the same temperature.
In summary, enhancement of charge carrier dynamics in nanocrystalline $\mathrm{Li}_{2} \mathrm{O}_{2}$ is most likely related to various defects and strain that high-energy ball milling can introduce. Defects are introduced in both the bulk and the surface-influenced regions of the nanocrystallites. In many cases the large volume fraction of interfacial regions formed during the mechanical impact show structural disorder facilitating ion transport over short and long distances. Although the enhancement is easily measurable, compared to other oxidic lithium ion conductors it turned out to be much lower. It seems that ball-milling has a larger influence on $\sigma_{\text {eon }}$ than on $\sigma_{\text {ion; }}$ at room temperature we found $\sigma_{\text {ion }} / \sigma_{\text {eon }} \approx 10$, which is much smaller than the ratio estimated for the microcrystalline counterpart.

\section{Author contributions}

The authors were equally involved in experimental work, data analysis and project planning. All authors have approved the final version of the manuscript.

\section{Acknowledgements}

We thank our colleagues at the TU Graz for valuable discussions. Financial support from the Austrian Federal Ministry of Economy, Family and Youth, and the Austrian National Foundation for Research, Technology and Development is greatly appreciated. Furthermore, we thank the Deutsche Forschungsgemeinschaft (DFG) for financial support within the DFG Research Unit 1277, grant no. WI3600/2-1 and 4-1, and the DFG Prority Program 1415, grant no. WI3600/5-1.

\section{References}

1 S. H. Oh, R. Black, E. Pomerantseva, J.-H. Lee and L. F. Nazar, Nat. Chem., 2012, 4, 1004.

2 K. M. Abraham and Z. Jiang, J. Electrochem. Soc., 1996, 1, 143.

3 Y.-C. Lu, B. M. Gallant, D. G. Kwabi, J. R. Harding, R. R. Mitchell, M. S. Whittingham and Y. Shao-Horn, Energy Environ. Sci., 2013, 6, 750.

4 F. Li, H. Kitaura and H. Zhou, Energy Environ. Sci., 2013, 6, 2302.

5 B. D. Adams, C. Radtke, R. Black, M. L. Trudeau, K. Zaghib and L. F. Nazar, Energy Environ. Sci., 2013, 6, 1772.

6 B. Scrosati, J. Hassoun and Y.-K. Sun, Energy Environ. Sci., 2011, 4, 3287.

7 P. G. Bruce, S. A. Freunberger, L. J. Hardwick and J.-M. Tarascon, Nat. Mater., 2012, 11, 19.

8 M. M. Thackeray, C. Wolverton and E. D. Isaacs, Energy Environ. Sci., 2012, 5, 7854.

9 J. Read, J. Electrochem. Soc., 2002, 149, A1190.

10 T. Ogasawara, A. Débart, M. Holzapfel, P. Novák and P. G. Bruce, J. Am. Chem. Soc., 2006, 128, 1390.

11 L. Zhong, R. R. Mitchell, Y. Liu, B. M. Gallant, C. V. Thompson, J. Y. Huang, S. X. Mao and Y. ShaoHorn, Nano Lett., 2013, 13, 2209. 
12 G. Girishkumar, B. McCloskey, A. C. Luntz, S. Swanson and W. Wilcke, J. Phys. Chem. Lett., 2010, 1, 2193.

13 S. A. Freunberger, Y. Chen, Z. Peng, J. M. Griffin, L. J. Hardwick, F. Bardé, P. Novák and P. G. Bruce, J. Am. Chem. Soc., 2011, 133, 8040.

14 F. Mizuno, S. Nakanishi, Y. Kotani, S. Yokoishi and H. Iba, Electrochemistry, 2010, 78, 403.

15 B. D. McCloskey, D. S. Bethune, R. M. Shelby, G. Girishkumar and A. C. Luntz, J. Phys. Chem. Lett., 2011, 2, 1161.

16 W. Xu, J. Hu, M. H. Engelhard, S. A. Towne, J. S. Hardy, J. Xiao, J. Feng, M. Y. Hu, J. Zhang, F. Ding, et al., J. Power Sources, 2012, 215, 240.

17 M. M. Ottakam Thotiyl, S. A. Freunberger, Z. Peng and P. G. Bruce, J. Am. Chem. Soc., 2013, 135, 494.

18 W. Xu, K. Xu, V. V. Viswanathan, S. A. Towne, J. S. Hardy, J. Xiao, Z. Nie, D. Hu, D. Wang and J.-G. Zhang, J. Power Sources, 2011, 196, 9631.

19 M. M. Ottakam Thotiyl, S. A. Freunberger, Z. Peng, Y. Chen, Z. Liu and P. G. Bruce, Nat. Mater., 2013, 12, 1050.

20 S. A. Freunberger, Y. Chen, N. E. Drewett, L. J. Hardwick, F. Bardé and P. G. Bruce, Angew. Chem., Inter. Ed., 2011, 50, 8609.

21 B. D. McCloskey, A. Speidel, R. Scheffler, D. C. Miller, V. Viswanathan, J. S. Hummelshøj, J. K. Nørskov and A. C. Luntz, J. Phys. Chem. Lett., 2012, 3, 997.

22 J. S. Hummelshoj, A. C. Luntz and J. K. Norskov, J. Phys. Chem., 2013, 138, 034703.

23 V. Viswanathan, K. S. Thygesen, J. S. Hummelshhøj and G. G. J. K. Nørskov, J. Chem. Phys., 2011, 135, 214704.

24 M. D. Radin and D. J. Siegel, Energy Environ. Sci., 2013, 6, 2370.

25 S. Kang, Y. Mo, S. P. Ong and G. Ceder, Chem. Mater., 2013, 25, 3328.

26 Y. Chen, S. A. Freunberger, Z. Peng, O. Fontaine and P. G. Bruce, Nat. Chem., 2013, 5, 489.

27 A. C. Luntz, V. Viswanathan, J. Voss, J. B. Varley, J. K. Nørskov, R. Scheffler and A. Speidel, J. Phys. Chem. Lett., 2013, 4, 3494.

28 R. R. Mitchel, B. M. Gallant, Y. Shao-Horn and C. V. Thompson, J. Phys. Chem. Lett., 2013, 4, 1060.

29 Y.-C. Lu and Y. Shao-Horn, J. Phys. Chem. Lett., 2012, 4, 93. 30 V. Timoshevskii, Z. Feng, K. H. Bevan, J. Goodenough and K. Zaghib, Appl. Phys. Lett., 2013, 103, 073901.

31 D. Zhai, H.-H. Wang, J. Yang, K. C. Lau, K. Li, L. A. Curtiss and K. Amine, J. Am. Chem. Soc., 2013, 135, 15364.

32 J. S. Hummelshøj, J. Blomqvist, S. Datta, T. Vegge, J. Rossmeisl, K. S. Thygesen, A. C. Luntz, K. W. Jacobsen and J. K. Nørskov, J. Chem. Phys., 2010, 132, 071101.

33 J. Chen, J. S. Hummelshøj, K. S. Thygesen, J. S. G. Myrdal, J. K. Nørskov and T. Vegge, Catal. Today, 2011, 165, 2.

34 S. P. Ong, Y. Mo and G. Ceder, Phys. Rev. B: Condens. Matter Mater. Phys., 2012, 85, 081105.

35 M. D. Radin, J. F. Rodriguez, F. Tian and D. J. Siegel, J. Am. Chem. Soc., 2012, 134, 1093.

36 F. Tian, M. D. Radin and D. J. Siegel, Chem. Mater., 2014, in press.
37 O. Gerbig, R. Merkle and J. Maier, Adv. Mater., 2013, 25, 3129.

38 E. Fukushima and S. B. W. Roeder, Experimental Pulse NMR: A Nuts and Bolts Approach, Addison-Wesley Pub. Co., Advanced Book Program, Reading, Mass., 1981.

39 P. Heitjans, A. Schirmer, and S. Indris, in Diffusion in Condensed Matter, ed. P. Heitjans and J. Kärger, Springer, 2005, ch. 9, p. 367.

40 A. Kuhn, S. Narayanan, L. Spencer, G. R. Goward, V. Thangadurai and M. Wilkening, Phys. Rev. B: Condens. Matter Mater. Phys., 2011, 83, 94302.

41 A. Kuhn, J.-Y. Choi, L. Robben, F. Tietz, M. Wilkening and P. Heitjans, Z. Phys. Chem., 2012, 226, 525.

42 H. Buschmann, J. Dölle, S. Berendts, A. Kuhn, P. Bottke, M. Wilkening, P. Heitjans, A. Senyshyn, H. Ehrenberg, A. Lotnyk, et al., Phys. Chem. Chem. Phys., 2011, 13, 19378. 43 D. Ailion and C. P. Slichter, Phys. Rev. Lett., 1964, 12, 168.

44 C. P. Slichter and D. Ailion, Phys. Rev., 1964, 135, A1099. 45 D. C. Ailion and C. P. Slichter, Phys. Rev., 1965, 137, A235. 46 D. C. Look and I. J. Lowe, J. Chem. Phys., 1966, 44, 2995. 47 T. J. Rowland and F. Y. Fradin, Phys. Rev., 1969, 182, 760. 48 D. Wolf, Phys. Rev. B: Condens. Matter Mater. Phys., 1974, 10, 2724 .

49 X.-P. Tang and Y. Wu, J. Magn. Reson., 1998, 133, 155.

50 R. Böhmer, J. Magn. Reson., 2000, 147, 78.

51 F. Qi, G. Diezemann, H. Böhm, J. Lambert and R. Böhmer, J. Magn. Reson., 2004, 169, 225.

52 F. Qi, T. Jörg and R. Böhmer, Solid State Nucl. Magn. Reson., 2002, 22, 484.

53 M. Wilkening and P. Heitjans, Phys. Rev. B: Condens. Matter Mater. Phys., 2008, 77, 024311.

54 J. Jeener and P. Broekaert, Phys. Rev., 1967, 157, 232.

55 R. Böhmer, K. Jeffrey and M. Vogel, Prog. Nucl. Magn. Reson. Spectrosc., 2007, 50, 87.

56 P. Bottke, D. Freude and M. Wilkening, J. Phys. Chem. C, 2013, 117, 8114.

57 L. S. Cahill, R. Chapman, J. Britten and G. Goward, J. Phys. Chem. B, 2006, 110, 7171.

58 Z. Xu and J. Stebbins, Science, 1995, 270, 1332.

59 C. Grey and N. Dupré, Chem. Rev., 2004, 104, 4493.

60 J. Cabana, N. Dupré, G. Rousse, C. P. Grey and M. R. Palacin, Solid State Ionics, 2005, 176, 2205.

61 S. Indris, D. Bork and P. Heitjans, J. Mater. Synth. Process., 2000, 8, 245.

62 K. Funke, C. Cramer and D. Wilmer, in Diffusion in Condensed Matter - Methods, Materials, Models, ed. P. Heitjans and J. Kärger, Springer, Berlin, 2nd edn, 2005, ch. 21, pp. 857-893.

63 P. Heitjans, M. Masoud, A. Feldhoff and M. Wilkening, Faraday Discuss., 2007, 134, 67.

64 B. Ruprecht, M. Wilkening, R. Uecker and P. Heitjans, Phys. Chem. Chem. Phys., 2012, 14, 11974.

65 B. Ruprecht, H. Billetter, U. Ruschewitz and M. Wilkening, J. Phys.: Condens. Matter, 2010, 22, 245901.

66 D. L. Sidebottom, Rev. Mod. Phys., 2009, 81, 999.

67 K. Funke, Prog. Solid State Chem., 1993, 22, 111. 
68 A. Bunde, W. Dieterich, P. Maass and M. Meyer, in Diffusion in Condensed Matter - Methods, Materials, Models, ed. P. Heitjans and J. Kärger, Springer, Berlin, 2nd edn, 2005, ch. 20, pp. 813-856.

69 J. T. S. Irvine, D. C. Sinclair and A. R. West, Adv. Mater, 1990, 2, 132.

70 D. L. Sidebottom, Phys. Rev. Lett., 1999, 82, 3653.

71 B. Roling, Solid State Ionics, 1998, 105, 185.

72 K. Ngai and R. W. Rendell, Phys. Rev. B: Condens. Matter Mater. Phys., 2000, 61, 9393.

73 M. Leskes, N. Drewett, L. Hardwick, P. Bruce, G. Goward and C. Grey, Angew. Chem., Int. Ed., 2012, 51, 8560.

74 M. Wilkening, S. Indris and P. Heitjans, Phys. Chem. Chem. Phys., 2003, 5, 2225.

75 N. Kamaya, K. Homma, Y. Yamakawa, M. Hirayama, R. Kanno, M. Yonemura, T. Kamiyama, Y. Kato, S. Hama, K. Kawamoto, et al., Nat. Mater., 2011, 10, 682.

76 R. Murugan, V. Thangadurai and W. Weppner, Angew. Chem., Int. Ed., 2007, 46, 7778.

77 H.-J. Deiseroth, S.-T. Kong, H. Eckert, J. Vannahme, C. Reiner, T. Zaiss and M. Schlosser, Angew. Chem., Int. Ed., 2008, 47, 755.

78 R. Amin, J. Maier, P. Balaya, D. P. Chen and C. T. Lin, Solid State Ionics, 2008, 179, 1683.

79 M. Wilkening, V. Epp, A. Feldhoff and P. Heitjans, J. Phys. Chem. C, 2008, 112, 9291.

80 M. Wilkening, W. Iwaniak, J. Heine, V. Epp, A. Kleinert, M. Behrens, G. Nuspl, W. Bensch and P. Heitjans, Phys. Chem. Chem. Phys., 2007, 9, 6199.

81 S. Narayanan, V. Epp, M. Wilkening and V. Thangadurai, RSC Adv., 2012, 2, 2553.

82 J. Langer, V. Epp, P. Heitjans, F. A. Mautner and M. Wilkening, Phys. Rev. B: Condens. Matter Mater. Phys., 2013, 88, 094304.

83 V. Epp, z. Gün, H.-J. Deiseroth and M. Wilkening, J. Phys. Chem. Lett., 2013, 4, 2118.

84 P. Heitjans and M. Wilkening, Mater. Res. Bull., 2009, 34, 915.
85 S. Indris and P. Heitjans, J. Non-Cryst. Solids, 2002, 307, 555.

86 P. Heitjans, A. Schirmer and S. Indris, in Diffusion in Condensed Matter - Methods, Materials, Models, ed. P. Heitjans and J. Kärger, Springer, Berlin, 2nd edn, 2005b, ch. 9, pp. 369-415.

87 M. Wilkening and P. Heitjans, ChemPhysChem, 2012, 13, 53.

88 F. Preishuber-Pflügl, P. Bottke, B. Bitschnau and M. Wilkening, Phys. Chem. Chem. Phys., 2014, in press.

89 D. Bork and P. Heitjans, J. Phys. Chem. B, 1998, 102, 7303.

90 D. Bork and P. Heitjans, J. Phys. Chem. B, 2001, 105, 9162.

91 M. Wilkening, D. Bork, S. Indris and P. Heitjans, Phys. Chem. Chem. Phys., 2002, 4, 3246.

92 M. Masoud and P. Heitjans, Defect Diffus. Forum, 2005, 237240, 1016.

93 X.-P. Tang, R. Busch, W. Johnson and Y. Wu, Phys. Rev. Lett., 1998, 81, 5358.

94 X.-P. Tang, U. Geyer, R. Busch, W. Johnson and Y. Wu, Nature, 1999, 402, 160.

95 R. Böhmer, T. Jörg, F. Qi and A. Titze, Chem. Phys. Lett., 2000, 316, 419.

96 M. Wilkening, W. Küchler and P. Heitjans, Phys. Rev. Lett., 2006, 97, 065901.

97 M. Wilkening and P. Heitjans, J. Phys.: Condens. Matter, 2006, 18, 9849.

98 M. Wilkening, C. Lyness, A. R. Armstrong and P. G. Bruce, J. Phys. Chem. C, 2009, 113, 4741.

99 M. Wilkening, J. Heine, C. Lyness, A. R. Armstrong and P. G. Bruce, Phys. Rev. B: Condens. Matter Mater. Phys., 2009, 80, 064302.

100 H. Mehrer, Diffusion in Solids, Springer, Berlin, 2006.

101 W. T. Geng, B. L. He and T. Ohno, J. Phys. Chem. C, 2013, 117, 25222.

102 J. Maier, Prog. Solid State Chem., 1995, 23, 171.

103 J. Maier, Nat. Mater., 2005, 4, 805.

104 N. Sata, K. Eberman, K. Eberl and J. Maier, Nature, 2000, 408, 946.

105 W. Puin, S. Rodewald, R. Ramlau, P. Heitjans and J. Maier, Solid State Ionics, 2000, 131, 159. 